\title{
The Response of Tropical Cyclone Intensity to Temperature Profile
}

\section{Change}

James M. Done ${ }^{1,2, *}$ Gary M. Lackmann ${ }^{3, *}$, Andreas F. Prein ${ }^{1}$

${ }^{1}$ National Center for Atmospheric Research, 3090 Center Green Drive, Boulder, Colorado 80301, USA

$5 \quad{ }^{2}$ Willis Research Network, 51 Lime St, London, EC3M 7DQ, UK

${ }^{3}$ Department of Marine, Earth and Atmospheric Sciences, North Carolina State University, Raleigh, North Carolina 27607, USA

* These authors contributed equally to this work.

10 Correspondence to: James M. Done (done@ucar.edu) 
Abstract. Theory indicates that tropical cyclone intensity should respond to changes in the vertical temperature profile.

15 While the sensitivity of tropical cyclone intensity to sea surface temperature is well understood, less is known about sensitivity to the temperature profile. In this paper, we combine historical data analysis and idealised modelling to explore the extent to which historical tropospheric warming and lower stratospheric cooling can explain observed trends in the tropical cyclone intensity distribution. Observations and modelling agree that historical global temperature profile changes coincide with higher lifetime maximum intensities. But observations suggest the response depends on the tropical cyclone intensity itself. Historical lower- and upper-tropospheric temperatures in hurricane environments have warmed significantly faster than the tropical mean. In addition, hurricane-strength storms have intensified at twice the rate of weaker storms per unit warming at the surface and at 300-hPa. Idealized simulations respond in the expected sense to various imposed changes in the temperature profile and agree with tropical cyclones operating as heat engines. Yet lower stratospheric temperature changes have little influence. Idealised modelling further shows an increasing altitude of the TC outflow but little change in outflow temperature. This enables increased efficiency for strong tropical cyclones despite the warming upper troposphere. Observed sensitivities are generally larger than modelled sensitivities, suggesting that observed tropical cyclone intensity change responds to a combination of the temperature profile change and other environmental factors.

Non-Technical Summary. Understanding how tropical cyclones (TCs) are changing is key for the protection of lives and

30 livelihoods in vulnerable regions. We know that warm oceans generally favour TC activity. Less is known about the role of air temperature above the oceans and extending into the lower stratosphere. Our analysis of historical records and computer simulations suggests that TCs strengthen in response to historical temperature change while also being influenced by other environmental factors.

\section{Introduction}

Understanding how tropical cyclones (TCs) and their impacts respond to climate change is of critical scientific and societal importance (e.g., Knutson et al., 2020). However, TC response to environmental change is complex and multi-faceted. Here, we use observations and idealized models to examine the TC response to changes in the environmental temperature profile.

40 Historical global surface temperature trend analyses show significant warming since the mid 1970s, attributed to anthropogenic forcing (Meehl et al., 2004; 2012). Yet trends in the vertical thermal structure and their attribution are less well understood (O'Gorman and Singh, 2013; Prein et al., 2017). Since the mid 1970s most datasets show that the troposphere has warmed while the lower stratosphere has cooled (e.g., Thompson et al., 2012; Philipona et al., 2018). However, analysing these trends is particularly challenging in the global tropics because of sparse long-term historical temperature profile records and the potential for artificial trends driven by observing system changes (Thorne et al., 2011). 
Indeed, Vecchi et al. (2013) showed marked differences in the magnitude of the thermal changes among a collection of observational and reanalysis datasets.

Uncertainty in temperature trends also arises from the complexity of the driving mechanisms and their representation in 50 reanalyses (Emanuel et al., 2013; Vecchi et al., 2013) and in general circulation models (GCMs). An historical warming maximum in the upper troposphere can be explained through moist adiabatic ascent above warming oceans and has been attributed to increasing greenhouse gas forcing (Santer et al., 2005; 2008). A shift in the moist adiabat corresponds to a larger warming aloft than at the surface. For the lower stratosphere, a strengthened Brewer-Dobson circulation has been proposed as a mechanism contributing to the cooling (Butchart, 2014). Here, cooling occurs through enhanced adiabatic cooling and reduced ozone concentration due to upwelling of ozone-poor tropospheric air. At the same time, observed step changes in cooling have been attributed to the volcanic eruptions of El Chichón in 1982 and Mt. Pinatubo in 1991 (Fujiwara et al., 2015). Ramaswamy et al. (2006) isolated the role of changes in ozone, carbon dioxide, aerosols, and solar radiation in observed lower stratospheric cooling, concluding that anthropogenic factors were the driver of overall cooling between the late 1970 s and the early 2000 s.

60

The representation of these complex mechanisms differs among GCMs and may contribute to the wide range in the magnitude of GCM-simulated profile changes (Cordero and Forster, 2006; Santer et al., 2008; Gettelman et al., 2010; Hill and Lackmann, 2011; Hardiman et al., 2014). GCMs are generally unable to reproduce observed profile change at the uppermost tropospheric levels (Po-Chedley and Fu, 2012; Mitchell et al., 2013), though whether this is due to model or 65 observational error remains unclear. This large spread among models and disagreement with observations may limit our ability to project tropical cyclone (TC) intensity. Emanuel et al. (2013) conclude that tropopause layer cooling contributed to increased TC potential intensity in the North Atlantic basin, and that improved process representation of profile changes in GCMs is critically needed to improve TC projections.

70 As the thermal profile has changed, so has the distribution of global TC intensity (e.g., Kossin et al., 2013; Sobel et al., 2016). A recent analysis of a homogeneous historical TC intensity record from 1979 to 2017 has revealed a statistically robust increase in global lifetime maximum intensity (Kossin et al., 2020). The observed intensity distribution has not simply shifted to higher intensities, but has become increasingly bimodal (Holland and Bruyère, 2014; Jewson and Lewis, 2020).

75 These changes in the TC intensity distribution may be attributable to a variety of environmental and internal processes, including both natural and anthropogenic effects. Changes in vertical wind shear (Ting et al., 2019), humidity (Dai, 2006), sea-surface temperature (SST), environmental temperature profile, and the nature of incipient disturbances may all contribute to TC intensity change. It is also understood that the observational datasets used in these analyses have limitations (e.g., Landsea et al., 2006; Klotzbach and Landsea, 2015), although recent efforts have reduced these uncertainties (e.g., Knutson 
80 et al., 2019; Kossin et al., 2020; Emanuel, 2021). TC intensity sensitivity to the underlying SST, or more accurately the thermal disequilibrium between the SST and the near surface atmosphere, is relatively well understood (Emanuel, 1987; Elsner et al., 2008; Strazzo et al., 2015). Global average TC intensity scales by $2.5 \%$ per degree Kelvin SST warming (Knutson et al., 2019). Yet the magnitude and mechanistic response of TC intensity to changes in the vertical profile of temperature are less well understood.

A Carnot heat engine has been used to link TC intensity to the vertical temperature profile (Emanuel, 1986; 1991; 2006; Ramsay, 2013; Pauluis and Zhang, 2017). This maximum potential intensity (PI) theory suggests that maximum TC intensity changes in response to the engine's efficiency - the temperature difference between the surface and the level of the TC outflow (e.g., Emanuel 1988; Holland 1997). Numerical experiments agree (Shen et al., 2000; Bryan and Rotunno, 2009a;

90 Emanuel and Rotunno, 2011). In idealised axisymmetric simulations under radiative convective equilibrium, PI increased by about $1 \mathrm{~ms}^{-1}$ per degree of lower stratospheric cooling, and by about $2 \mathrm{~ms}^{-1}$ per degree of surface warming (Ramsay, 2013). While lower stratospheric cooling revs the Carnot engine by increasing thermodynamic efficiency and potential intensity, the warming maximum in the upper troposphere has the opposite effect and limits TC intensification associated with ocean warming (Shen et al., 2000; Hill and Lackmann, 2011; Tuleya et al., 2016). The spread in historical temperature trends across reanalysis datasets also results in a spread in PI trends (Emanuel et al., 2013).

Yet the realized response of the TCs themselves may be quite different from the response of the PI. Idealized GCM simulations (Vecchi et al., 2013) did not show significant sensitivity of the TC intensity distribution to lower stratospheric cooling despite an increasing PI. The TC intensity distribution did, however, respond to temperature perturbations in the 100 upper troposphere, corresponding with PI changes. Furthermore, the realized response of TCs appears to depend on the TC intensity itself. Indeed, the highest sensitivity to surface warming resides in the strongest storms (e.g., Elsner et al., 2008; Knutson et al., 2010).

We hypothesize that observed tropical temperature profile changes exert predictable influences on TC intensity 105 characteristics including intensification rate and maximum intensity. Furthermore, we explore whether historic temperature profile changes are sufficient to explain past trends in the TC intensity distribution. Our approach blends historical data analysis with idealized numerical modelling. Observational analyses bring together a global homogenized radiosonde temperature dataset with a homogeneous TC intensity record to minimize contamination by artificial trends. Naturally, observed trends in TC intensity are not due to changes in temperature alone, and respond to changes in other environmental

110 factors. Our goal is to isolate the influence of temperature change on TC intensity. We focus on a global-scale analysis over a 37-year historical period - scales at which TC intensity should be more strongly constrained by thermodynamic change than by other environmental or geographic factors (Deser et al., 2012). Idealized numerical modelling further isolates and quantifies the TC intensity response to observed trends and future temperature profile changes. 
115 The next section describes the observation datasets and analysis procedures, and the numerical model experiments. Results of the observational analysis and idealized numerical model experiments are presented in Sect. 3. A synthesis and concluding discussion are provided in Sect. 4.

\section{Methods}

\subsection{Historical temperature and tropical cyclone datasets}

120 We use multiple temperature and TC datasets to characterise historical trends and the relationships between TC intensity and thermal structure. Temperature data are compared across radiosonde soundings and two reanalysis datasets and related to two historical TC datasets.

Global radiosonde data are obtained from the Radiosonde Observation Correction Using Reanalyses (RAOBCORE) v1.5.1, available on a $10^{\circ} \times 5^{\circ}$ grid, 16 pressure levels and twice daily (Haimberger, 2007; Haimberger et al., 2012). RAOBCORE was developed to be suitable for climate applications and was created by applying a time-series homogenization to the Integrated Global Radiosonde Archive (IGRA; Durre et al., 2006). This procedure uses temperature differences between radiosonde observations and background forecasts from the European Centre for Medium-Range Weather Forecasts (ECMWF) Re-Analysis (ERA-40, Uppala et al., 2005) to correct discontinuities tied to observing system changes and remove persistent biases. These corrections are particularly important for lower stratospheric temperatures where measurements are susceptible to radiation errors (Sherwood et al., 2005). Haimburger et al. (2008) showed that RAOBCORE compares favourably with satellite-derived estimates of temperature trends in the upper troposphere and lower stratosphere consistent with theoretical and model expectations. Sounding profiles are sufficiently numerous to characterise the thermal structure from the $925 \mathrm{hPa}$ level up to $50 \mathrm{hPa}$. While sounding locations in TC genesis regions are sparse, their spatial representativeness for temperature scales with the large radius of deformation at low latitudes. In addition, we only use stations that have at least $70 \%$ complete records over the period 1981 to 2017 and do not contain breakpoints. Breakpoints are detected following the methodology described in Prein and Heymsfield (2020). Briefly, four different breakpoint detection algorithms are applied and time series for which more than two algorithms identified a breaking point in the same year were excluded.

The two reanalysis datasets analysed here, both produced by the ECMWF, are the Interim reanalysis (ERA-I; Dee et al., 2011; accessed from European Centre for Medium-Range Weather Forecasts, 2009) and the more recent ERA5 (Hersbach et al., 2020; accessed from European Centre for Medium-Range Weather Forecasts, 2019). These reanalyses differ in important ways that may affect trends in the vertical temperature profile, including horizontal and vertical grid spacing, model physics, 
145 data assimilation technique, and the data sources assimilated. The horizontal grid spacings are $79 \mathrm{~km} /$ TL255 (ERA-I) and 31 $\mathrm{km} /$ TL639 (ERA5), and the numbers of vertical levels and vertical extent are 60 levels up to $10 \mathrm{hPa}$ for ERA-I and 137 levels up to $1 \mathrm{hPa}$ for ERA5.

ERA-I and ERA5 assimilate vast quantities of in situ, radiosonde, and remote sensing observations, and the observing 150 systems change over time. This can lead to discontinuities in the simulated time series (Dee et al., 2011; Simmons et al., 2014). ERA-I assimilates the RAOBCORE data and ERA5 assimilates radiosonde data that have been homogenized using a newer procedure that uses neighbouring stations rather than departure statistics alone. ERA5 contains a pronounced cold bias in the lower stratosphere from 2000 to 2006 due to the use of inappropriate background error covariances (Hersbach et al., 2020; Simmons et al., 2020). This bias has been corrected in ERA5.1 (Simmons et al., 2020; accessed from European Centre

155 for Medium-Range Weather Forecasts, 2020). For our analysis we join ERA5 and ERA5.1 by replacing ERA5 with ERA5.1 for the years 2000 to 2006 and continue to refer to this joined dataset as ERA5.

Observations of historical TCs are taken from two sources: The international best track archive for climate stewardship version 4 (IBTrACS, Knapp et al., 2010, downloaded on June 14, 2021) and a reanalysed intensity record provided by

160 Kossin et al. (2020). The IBTrACS has formed the basis for many studies of TC variability and change. Here, we use USA agency data, which are largely derived from the National Hurricane Center's HURricane DATa 2nd generation (HURDAT2) dataset and reports from the Joint Typhoon Warning Center. However, spatial and temporal variations in the instrumental observing system challenge the interpretation of TC variability and change, particularly in the early record (e.g., Landsea et al., 2006; Klotzbach and Landsea, 2015). Indeed, substantial differences across the reporting agencies (Knapp and Kruk,

165 2010) can contaminate global climatologies (Schreck et al., 2014). In response, Kossin et al. (2013) reanalysed the historical intensity record by applying an intensity algorithm (the advanced Dvorak Technique, ADT) to a homogenized geostationary satellite dataset (the Hurricane Satellite record, HURSAT). The resulting ADT-HURSAT dataset was recently extended to cover the period 1979 to 2017 (Kossin et al., 2020). The key advantage of ADT-HURSAT compared to IBTrACS is its consistency in time and space which makes it suitable for trend analysis, especially from 1981 onwards. Both TC datasets

170 are included here to demonstrate sensitivity of TC intensity change to artifacts of the datasets, and to connect results back to prior work.

The 37-year observational analysis period of 1981 to 2017 is chosen as a balance between data availability and to roughly coincide with the start of the recent warming trend (e.g., Rahmstorf et al., 2017, their Fig. 2) and its influence on global TC

175 behaviour (Holland and Bruyère, 2014). Where possible, we use minimum central sea level pressure $\left(P_{\min }\right)$ as a measure of storm intensity, though for some analyses we also use maximum $10 \mathrm{~m}$ wind speeds $\left(V_{\max }\right)$. The advantages of $P_{\min }$ over $V_{\max }$ are discussed by Klotzbach et al. (2020), including a significantly higher correlation with normalized TC damage. 


\subsection{Idealized model experiments}

We hypothesize that observed tropical temperature profile changes exert predictable influences on trends in the intensification rate and maximum intensity of TCs. As discussed above, previous studies have explored the sensitivity of TC intensity to both the tropical upper-tropospheric warming maximum and lower stratospheric cooling. From the conceptual framework of a Carnot heat engine, an upper tropospheric warming maximum in the ambient TC environment reduces the thermodynamic efficiency of a TC by warming the outflow temperature, especially for weaker TCs with lower altitude outflow (rising, saturated air parcels experience a lower equilibrium level). Lower stratospheric cooling, on the other hand, could increase thermodynamic efficiency, owing to colder outflow temperatures, particularly for stronger TCs with higher altitude outflow (this would increase the altitude of a parcel's equilibrium level). We use ensembles of simulations from an axisymmetric model to test these predictions, and to quantify the magnitude of these influences on TC intensity.

The axisymmetric TC capability of Cloud Model 1 (CM1, Bryan and Fritsch, 2002; Bryan and Rotunno, 2009a) is well suited for our experiments. The limitations of axisymmetric simulations are outweighed by the reduced computational expense, which allows us to run ensembles of simulations. Axisymmetric models have proven useful in the evaluation of TC maximum intensity (e.g., Rotunno and Emanuel, 1987; Bryan and Rotunno, 2009a; Hakim, 2011; Rousseau-Rizzi and Emanuel, 2019). We acknowledge that some three-dimensional effects, such as vortex Rossby waves, are known to be important to TC intensity (e.g., Wang, 2002; Gentry and Lackmann, 2010; Persing et al., 2013). There is no reason to believe that these factors would vary substantially in direct response to changes in the environmental temperature profile, but they could vary with storm intensity. Thus, the response of axisymmetric vortices to changes in the thermodynamic profile is deemed sufficient to test our hypotheses, but fully 3-dimensional simulations are needed to investigate this limitation. The axisymmetric domain in our simulations features $4 \mathrm{~km}$ grid length, a model top of $25 \mathrm{~km}$ (59 vertical levels), and a radial domain length of $768 \mathrm{~km}$. The horizontal mixing length in this version of CM1 is a linear function of surface pressure, varying from $100 \mathrm{~m}$ at $1015 \mathrm{hPa}$ to $1000 \mathrm{~m}$ at $900 \mathrm{hPa}$ (Bryan, 2012).

We initialize CM1 (version r19.10) with the Dunion (2011) "moist tropical" sounding, derived from western North Atlantic rawinsonde data from 1995 to 2002 (Fig. 1a). The model is initialized with a weak vortex ( 12 $\mathrm{ms}^{-1}$ maximum azimuthal velocity in gradient thermal wind balance) like that in the control simulation of Rotunno and Emanuel (1987). A potentially important difference between our experimental design and that of Rotunno and Emanuel (1987) is that our initial conditions are not in a state of radiative-convective equilibrium. This is to assess the influence of temperature profile differences more directly during the TC intensification stage, although we acknowledge that the TC begins to modify the environment immediately, and we have not eliminated this change in our simulations. Our present-day simulations feature an SST of $28^{\circ} \mathrm{C}$, close to the value obtained by lowering the 1000 -hPa air temperature in the Dunion moist-tropical sounding adiabatically to the surface ( $1015 \mathrm{hPa})$. Bryan and Rotunno (2009b, p. 3046) discuss their use of $28{ }^{\circ} \mathrm{C}$ SST in the control 
simulation of Bryan and Rotunno (2009a), citing Cione et al. (2000) for observational support for air-sea temperature differences.

We ran the simulations for 8 days, which allowed the idealized TCs to intensify to a maximum and then equilibrate to a 215 quasi-steady-state intensity. We recognize that much longer integrations have been used in several equilibrium studies (e.g., Hakim, 2011; Ramsay, 2013), but TC modification of the environment in longer integrations would limit our ability to detect environmental influences. Given our goal of examining TC responses to changes in the environmental temperature profile, we focus on the equilibrium state rather than the peak core strength (Rousseau-Rizzi et al., 2021), though we present both. Owing to the sensitivity of simulated TC intensity to various model parameterization choices, we ran an ensemble of 21 220 simulations for each environmental profile, varying the turbulence, radiation, sea surface and microphysical parameterizations (Tables 1, and A1). Despite temporal variability, the ensemble mean intensity appears close to the analytical value predicted by the Emanuel (1988) maximum potential intensity (E-PI, Table 2); we recognize that considerable uncertainty also exists in the E-PI values owing to various choices that go into that calculation.

225 Table 1: CM1 model physics ensemble namelist choices for the surface model (sfcmodel), ocean model (oceanmodel), surface exchange coefficients (isftcflx), atmospheric radiation (radopt), relaxation term that mimics atmospheric radiation (rterm), and explicit moisture scheme (ptype); see Table A1 for specific settings for each of the 21 ensemble members.

\begin{tabular}{cl}
\hline parameter & description \\
\hline sfcmodel & CM1 (1), "WRF" (2), "revised WRF" (3), GFDL (4), MYNN (6) \\
oceanmodel & constant SST (1), ocean mixed layer model (2) \\
isftcflx & Donelan (1), or Donelan/Garratt for Cd and Ce (2) \\
radopt & simple (0, with rterm = 1), NASA (1), or RRTMG (2) \\
ptype & Morrison (5) or Thompson (3)
\end{tabular}

230 Table 2: Ensemble experiments and maximum intensity (i.e., $\boldsymbol{P}_{\min }$ ); values are for time-filtered time series. For three right columns, numbers in parentheses represents standard deviation. A Butterworth low-pass time filter was applied to remove highfrequency fluctuations. Equilibrium period is for simulation hours 150 to 193; "complex" denotes the 13-member ensemble subset with complex radiation parameterization. Settings for the Emanuel potential intensity (E-PI) calculation, based on the pyPI software package (Gilford, 2021), include dissipative heating (Bister and Emanuel, 1998), an enthalpy-drag coefficient ratio of 0.9, and a wind reduction coefficient of 0.9 . 


\begin{tabular}{|c|c|c|c|c|c|}
\hline Experiment & SST & E-PI & $\begin{array}{l}\text { Simulation } P_{\min } \\
\text { (full ensemble) }\end{array}$ & $\begin{array}{l}\text { Simulation } P_{\min } \\
\quad \text { (complex) }\end{array}$ & $\begin{array}{c}\text { Equilibrium } P_{\min } \\
\text { (complex) }\end{array}$ \\
\hline Present-day & $\begin{array}{c}301.2 \mathrm{~K} \\
\left(28.0^{\circ} \mathrm{C}\right)\end{array}$ & $\begin{array}{l}923.4 \mathrm{hPa} \\
\left(74.7 \mathrm{~ms}^{-1}\right)\end{array}$ & $\begin{array}{l}917.8 \mathrm{hPa} \\
(10.8 \mathrm{hPa})\end{array}$ & $\begin{array}{c}913.3 \mathrm{hPa} \\
(8.7 \mathrm{hPa})\end{array}$ & $\begin{array}{l}920.5 \mathrm{hPa} \\
(10.9 \mathrm{hPa})\end{array}$ \\
\hline Mid-Century & $\begin{array}{c}301.8 \mathrm{~K} \\
\left(28.6^{\circ} \mathrm{C}\right)\end{array}$ & $\begin{array}{c}920.1 \mathrm{hPa} \\
\left(75.7 \mathrm{~ms}^{-1}\right)\end{array}$ & $\begin{array}{l}913.7 \mathrm{hPa} \\
(12.0 \mathrm{hPa})\end{array}$ & $\begin{array}{l}912.1 \mathrm{hPa} \\
(9.8 \mathrm{hPa})\end{array}$ & $\begin{array}{l}917.2 \mathrm{hPa} \\
(13.7 \mathrm{hPa})\end{array}$ \\
\hline $\begin{array}{l}\text { End of } \\
\text { Century }\end{array}$ & $\begin{array}{c}302.4 \mathrm{~K} \\
\left(29.2{ }^{\circ} \mathrm{C}\right)\end{array}$ & $\begin{array}{l}917.1 \mathrm{hPa} \\
\left(76.4 \mathrm{~ms}^{-1}\right)\end{array}$ & $\begin{array}{l}907.0 \mathrm{hPa} \\
(10.3 \mathrm{hPa})\end{array}$ & $\begin{array}{c}906.0 \mathrm{hPa} \\
(8.5 \mathrm{hPa})\end{array}$ & $\begin{array}{l}913.3 \mathrm{hPa} \\
(10.5 \mathrm{hPa})\end{array}$ \\
\hline $\begin{array}{c}\text { No upper } \\
\text { warming max }\end{array}$ & $\begin{array}{c}302.4 \mathrm{~K} \\
\left(29.2{ }^{\circ} \mathrm{C}\right)\end{array}$ & $\begin{array}{l}916.4 \mathrm{hPa} \\
\left(76.4 \mathrm{~ms}^{-1}\right)\end{array}$ & $\begin{array}{l}909.0 \mathrm{hPa} \\
(11.6 \mathrm{hPa})\end{array}$ & $\begin{array}{l}906.8 \mathrm{hPa} \\
(10.5 \mathrm{hPa})\end{array}$ & $\begin{array}{l}911.0 \mathrm{hPa} \\
(13.7 \mathrm{hPa})\end{array}$ \\
\hline $\begin{array}{c}\text { No stratos. } \\
\text { cooling }\end{array}$ & $\begin{array}{c}302.4 \mathrm{~K} \\
\left(29.2^{\circ} \mathrm{C}\right)\end{array}$ & $\begin{array}{c}917.1 \mathrm{hPa} \\
\left(76.4 \mathrm{~ms}^{-1}\right)\end{array}$ & $\begin{array}{l}909.5 \mathrm{hPa} \\
(12.0 \mathrm{hPa})\end{array}$ & $\begin{array}{c}906.5 \mathrm{hPa} \\
(8.8 \mathrm{hPa})\end{array}$ & $\begin{array}{l}916.2 \mathrm{hPa} \\
(13.3 \mathrm{hPa})\end{array}$ \\
\hline $\begin{array}{c}\text { GCM } \\
\text { RCP } 8.5\end{array}$ & $\begin{array}{l}304.5 \mathrm{~K} \\
\left(31.3^{\circ} \mathrm{C}\right)\end{array}$ & $\begin{array}{c}910.9 \mathrm{hPa} \\
\left(77.5 \mathrm{~ms}^{-1}\right)\end{array}$ & $\begin{array}{l}903.5 \mathrm{hPa} \\
(12.8 \mathrm{hPa})\end{array}$ & $\begin{array}{l}901.0 \mathrm{hPa} \\
(10.2 \mathrm{hPa})\end{array}$ & $\begin{array}{l}908.1 \mathrm{hPa} \\
(12.9 \mathrm{hPa})\end{array}$ \\
\hline
\end{tabular}

To explore the sensitivity of simulated TC intensity to changes in the environmental thermodynamic profile, we ran five additional 21-member ensemble experiments (Table 2). These were primarily designed to explore TC intensity response to extrapolated observational trends based on RAOBCORE data discussed in Sect. 2.1 and presented in Sect. 3.1. The "midcentury" experiment corresponds to conditions approximately in the year 2050 if current trends are extrapolated, and the "end-of-century" experiment applies changes extrapolated over a century-long period. Two additional experiments allow us to isolate the sensitivity of TC intensity to specific changes observed in tropical temperature profiles. The "no upper warming maximum" ensemble is based on a temperature change profile that is nearly constant with height in the troposphere (Fig. 1b), and the "no stratospheric cooling" simulations explore TC response to a temperature change profile that eliminates 245 lower stratospheric cooling (Fig. 1b). Recognizing the limitations in extrapolation of current observational trends, we ran an 
additional ensemble experiment based on a multi-model mean of IPCC AR5 GCM change profiles, for end-of-century conditions under the RCP8.5 scenario (see Jung and Lackmann, 2019, their Table 2).

Based on the thermodynamic and Carnot efficiency considerations mentioned in Sect. 1 and the E-PI calculations shown in Table 2, we predict a priori that the present-day simulation would produce the weakest ensemble-mean TC, followed in order of increasing intensity by the mid-century and end-of-century simulations. We further expect that simulations omitting the tropical upper warming maximum would be slightly stronger than the default end-of-century ensemble, and that the ensemble removing stratospheric cooling would be slightly weaker in intensity relative to the default end-of-century run. We expect the GCM-based ensemble to yield the strongest storm, given significantly greater warming. Of course, the numerical simulations are not constrained to agree with these theoretically motivated predictions.

To further test our hypotheses relating changes in TC intensity to environmental temperature changes, we computed thermodynamic efficiency following Emanuel (1987; 1988) and Gilford (2021). Given the availability of high-resolution numerical simulations, we also computed the simulated TC outflow temperature directly, defined as the temperature of air with outward radial flow exceeding $1.0 \mathrm{~ms}^{-1}$ and cloud ice mixing ratio exceeding $10^{-5} \mathrm{kgkg}^{-1}$. Experimentation with these threshold values demonstrates that this setting works well to represent the temperature of the cirrostratus outflow layer, though the ensemble average values obtained were not highly sensitive to changes in the radial velocity or cloud ice mixing ratio thresholds (not shown). In our analysis of derived outflow temperatures, we noted substantial differences between simulations conducted with "complex" versus "simple" representation of radiation and have stratified the results accordingly.
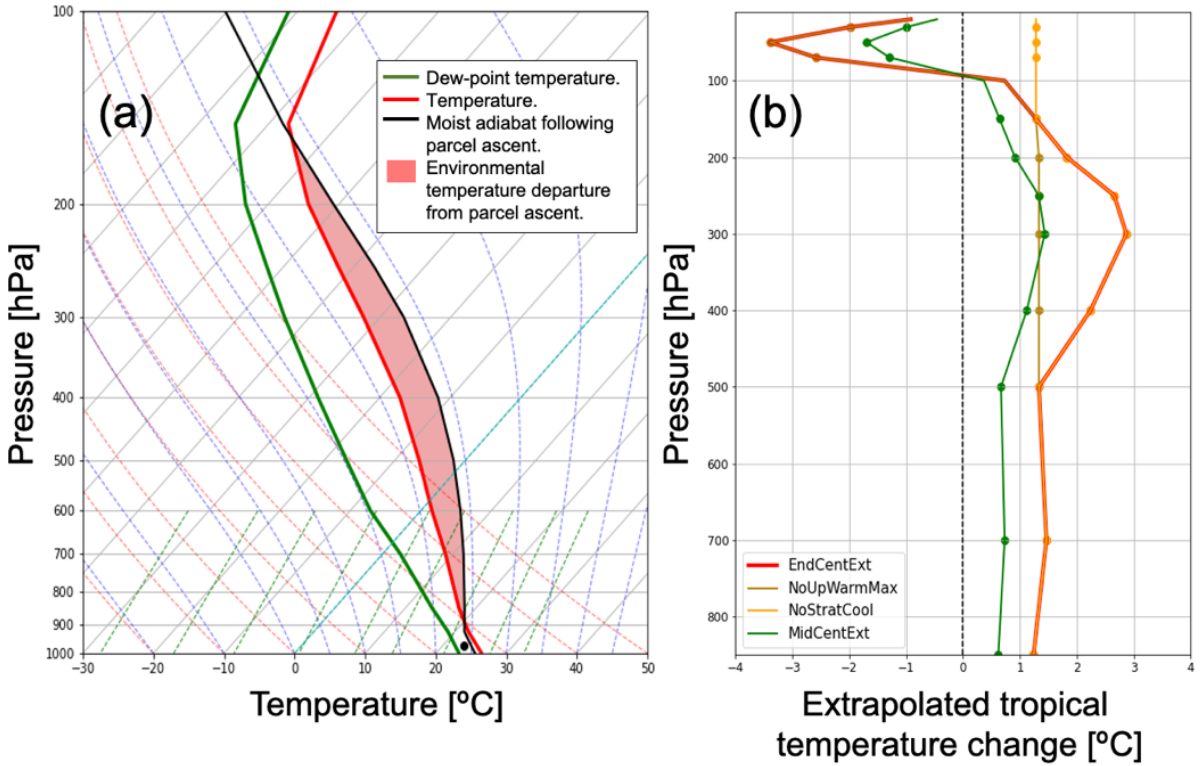

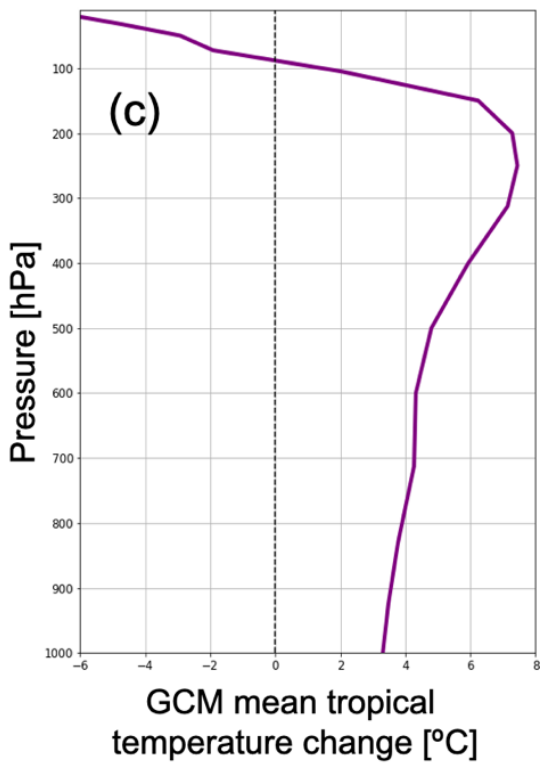


Figure 1: (a) Dunion (2011) Moist Tropical sounding; (b) Temperature change profiles extrapolated from hurricane-season tropical trends in the RAOBCORE database; (c) Corresponding tropical temperature change profile derived from an average of 21 CMIP5 GCMs under the RCP8.5 emission scenario. Note the differences in vertical axis ranges between the panels.

\section{Results}

\subsection{Historical temperature and tropical cyclone observations}

To begin exploring whether observed temperature profile changes are sufficient to explain observed trends in the TC intensity distribution, we start with an analysis of historical data. Historical summertime tropical temperature profile trends are compared across RAOBCORE, ERA5 and ERA-I in Fig. 2a. The known upper tropospheric warming maximum and lower stratospheric cooling are present across all three datasets but vary significantly in magnitude and vertical structure. As expected, ERA-I and RAOBCORE trend profiles agree well with each other (since ERA-I assimilates RAOBCORE data) with peak warming located at the $300 \mathrm{hPa}$ level. The ERA5 exhibits $30 \%$ weaker peak warming than RAOBCORE and locates peak warming higher in altitude, at $175 \mathrm{hPa}$. Cooling rates in the lower stratosphere are strongest in ERA5, reportedly due to the assimilation of radiosonde data adjusted by the RICH method (Haimberger et al., 2012; Hersbach et al., 2020). Simmons et al. (2014) suggest that the weaker cooling trend in ERA-I may be related to a cold bias in the lower stratosphere which persisted through the early 2000s and then was corrected through a new assimilation of radio occultation data.
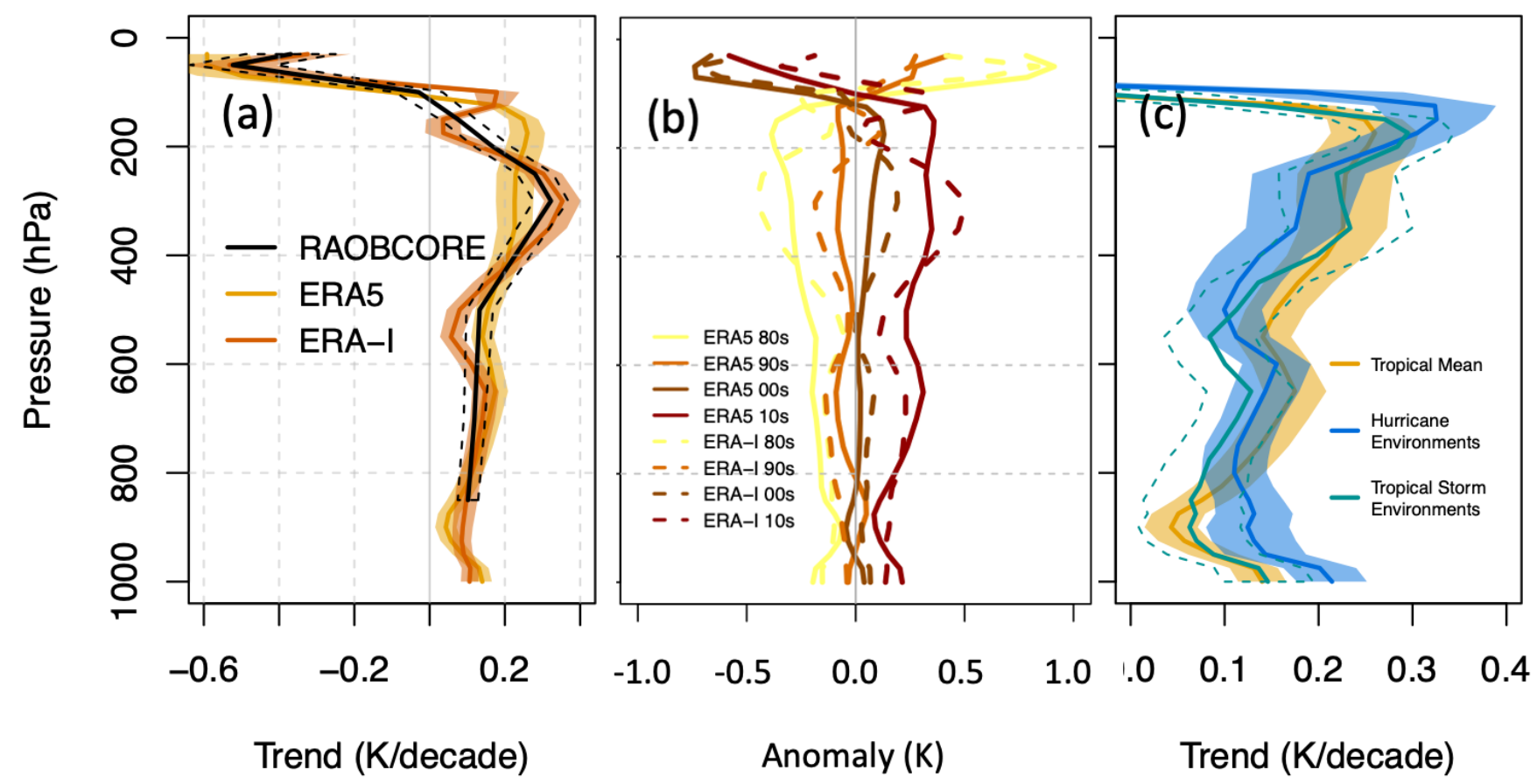

Trend (K/decade)

Anomaly (K) Trend (K/decade) 
Figure 2: Historical tropical temperature profiles averaged over $0^{\circ}$ to $20^{\circ} \mathrm{N}$ for Aug-Sept-Oct and $-20^{\circ} \mathrm{S}$ to $0^{\circ}$ for Dec-Jan-Feb using RAOBCORE, ERA5 and ERA-I shown as a) the linear trend over the period 1981 to2017 (K per decade), and b) departures of decadal averages from the 1981 to 2017 average (K) for ERA5 and ERA-I only. Decadal averages are calculated over the periods 1981 to 1989, 1990 to 1999, 2000 to 2009, and 2010 to 2017. c) as in a) for ERA5 and including trends for proximal environments for tropical storms (ADT-HURSAT LMI less than $33 \mathrm{~ms}^{-1}$ ) and for hurricane strength TCs (ADT-HURSAT LMI greater or equal to $33 \mathrm{~ms}^{-1}$ ). Proximal environments are defined as averages within a $0.5^{\circ}$ radius of the LMI locations two days before the TC arrives at the location using ERA5. Shading and dashed lines in a) and c) indicate plus/minus twice the standard error of the trend lines, approximating the $95 \%$ confidence interval.

We next examine whether the trend is stable across the decades, or whether the change concentrates in a particular decade. The rate of change in the temperature profile is roughly constant across the four decades throughout the troposphere (Fig. 2b). But decadal changes in the lower stratosphere are less stable, reflecting the known step changes in temperature linked to volcanic eruptions (Ramaswamy et al., 2006).

Figure $2 \mathrm{c}$ shows that temperature trends proximal to strong TCs are significantly different from trends for the tropics as a whole. Proximal is defined here as an average within $0.5^{\circ}$ of the LMI locations (according to ADT-HURSAT) two days before a TC arrives at the location. The sample sizes are 2174 tropical storm environments and 1774 hurricane environments. Strong TC environments have warmed significantly faster than the tropical mean environment below the 850-hPa level, warming twice as fast. The peak warming in the upper troposphere is correspondingly stronger and located at a higher level. The middle troposphere warms more slowly, but not significantly so. Trends also differ between proximal environments for tropical storms and hurricane strength storms, but not significantly so. Tropical storm environments also do not trend significantly differently from the tropical mean environment.

Our purpose here is not to comment on which temperature dataset produces the most accurate trends, but rather to document that the choice of temperature dataset matters for the magnitude and structure of the temperature trend. We also update previous work (Emanuel et al., 2013; Vecchi et al., 2013) that compared across reanalysis datasets by including the more recent ERA5 combined with ERA5.1. By extension, analysed relationships between TC intensity trends and temperature profile trends may also vary by choice of temperature dataset. Later in this section we make links between temperature trends and TC intensity trends. This requires a temperature dataset with globally uniform coverage. We choose the ERA5 dataset for this purpose given its higher spatial resolution and newer data assimilation procedures compared to ERA-I. We next turn our attention to the changing TC intensity distribution.

At the same time as the global tropical temperature profile has changed, so too has the distribution of global TC intensity. Figure 3a,b shows TC intensity distributions by historical decade in both the IBTrACS and ADT-HURSAT datasets. First, we first notice the different shaped distributions between IBTrACS and ADT-HURSDAT. Kossin et al. (2020) explain that cirrus-obscured TC eyes can cause underestimation of lifetime maximum intensity (LMI) at around $33 \mathrm{~ms}^{-1}$. It's likely that 
this dataset therefore over-reports LMI values less than $33 \mathrm{~ms}^{-1}$, with higher LMI only reported if the algorithm locks onto a clearing eye signature as TCs intensify. ADT-HURSAT therefore sacrifices storm-level accuracy for improved long-term statistics.
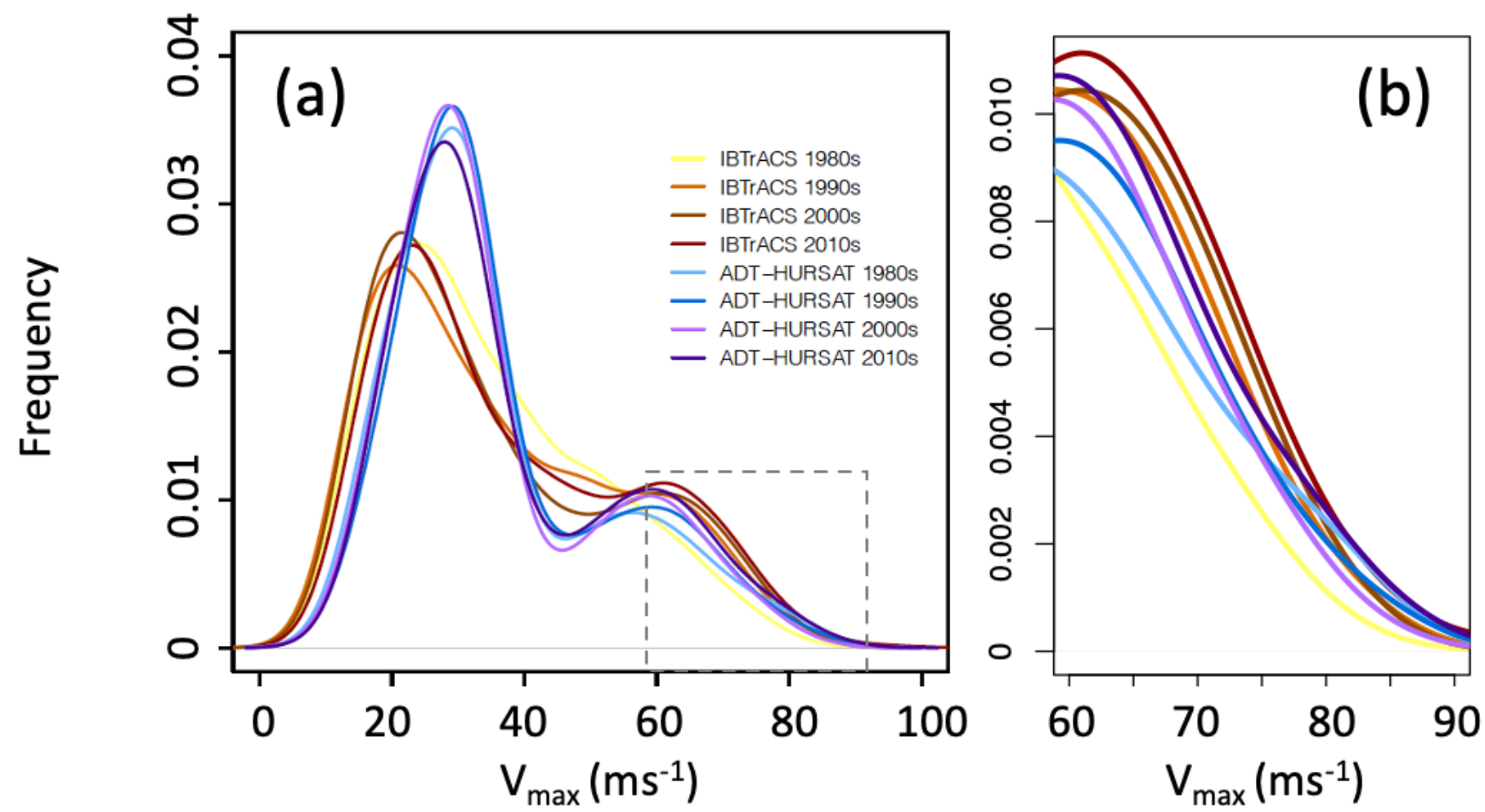

Figure 3: a,b) Distributions of global TC LMI (lifetime maximum 1-minute sustained wind speed at $10 \mathrm{~m}$ above the surface, $\mathrm{ms}^{-1}$ ) for the period 1981 to 2017 split by historical decade using IBTrACS and ADT-HURSAT. The exact years for each decadal period are 1981 to 1989,1990 to 1999,2000 to 2009 , and 2010 to 2017. Kernel density is estimated using Gaussian smoothing kernels with a standard deviation of $5 \mathrm{~ms}^{-1}$. Panel b) provides a close-up view of the portion of panel a) outlined by the grey dashed line.

The well-established bi-modal distribution is present in both datasets, and both reproduce the known result of an increasing proportion of the strongest storms over time (e.g., Elsner et al., 2008; Kossin et al., 2020). We also reproduce the stronger trends in IBTrACS than ADT-HURSAT. For the proportion of major hurricanes (category 3 and higher on the SaffirSimpson scale), Kossin et al. (2020) find the increase in ADT-HURSAT is about half that in IBTrACS and suggest that half the trend in IBTrACS is attributable to changes in observing systems. When considering the proportion of category 4 and 5 storms, we find even larger discrepancies. In IBTrACS, the proportion of category 4 and 5 storms increases from $11.3 \%$ in the 1980 s to $20.9 \%$ in the $2010 \mathrm{~s}$; a factor 1.85 increase. For ADT-HURSAT, the proportion increases from $14.1 \%$ in the 1980 s to $17.7 \%$ in the 2010 s; a factor of only 1.26 , and a rate approximately 3 times lower than in IBTrACS. Our finding here is consistent with the greater impact of observing system change for the strongest storms (Kossin et al., 2020). Interestingly, we also find that IBTrACS produces more than half the change between the first two decades (1980s to the 1990s), whereas ADT-HURSDAT produces more than half the change between the final two decades (2000s to the 2010s). 
Our purpose in reproducing and expanding upon known trends and discrepancies among datasets is to show that the choice of TC dataset matters for intensity trend magnitudes. The choice may be particularly important for trend analyses that subset trends by TC intensity.

345 We now begin to explore statistical linkages between the changing TC intensity and temperature profiles. We use quantile regression models to explore how the strength of the statistical relationship between LMI and environmental temperature varies by storm intensity, following the approach used in Elsner et al. (2008) and Kossin et al. (2013). Our quantile regression models specify how the LMI quantile changes with variation in temperature. This allows us to identify whether relationships with the temperature profile differ between strong and weak storms. We later compare these assessments to those derived from our numerical simulations.

We start by quantifying temporal trends in LMI to link back to existing work and provide a starting point from which to explore trends with respect to temperature. When considering all TCs (Fig. 4a), only those exceeding hurricane strength ( $>33$ $\mathrm{ms}^{-1}$ ) show intensification, but trends are not significantly different from zero. Kossin et al. (2020) report that quantile regression can be highly sensitive to the range of the data. When considering only hurricane strength storms (Fig. 4b) we found that intensification is significantly different from zero, peaking at $3 \mathrm{~ms}^{-1}$ per decade for a hurricane quantile of 0.4. These results reproduce those of Kossin et al. (2020).

We next explore how these trends in LMI quantiles compare to trends in the theoretical maximum potential intensity, to 360 determine how strong vs. weak storms have kept pace with trends in their PI. The theoretical maximum potential intensity is calculated using E-PI (Emanuel, 1988) on thermodynamic profiles from ERA5 data proximal to individual TCs at the time of LMI. The linear trend in mean E-PI is $1.2 \mathrm{~ms}^{-1}$ per decade for locations of all TCs and $0.9 \mathrm{~ms}^{-1}$ per decade for locations of hurricane strength TCs only. Given that tropical storm strength TCs show no temporal trend, they have not kept pace with their rising E-PI. But hurricane strength storms exhibit super-E-PI trends and have therefore closed the gap between realized and maximum potential intensity. 

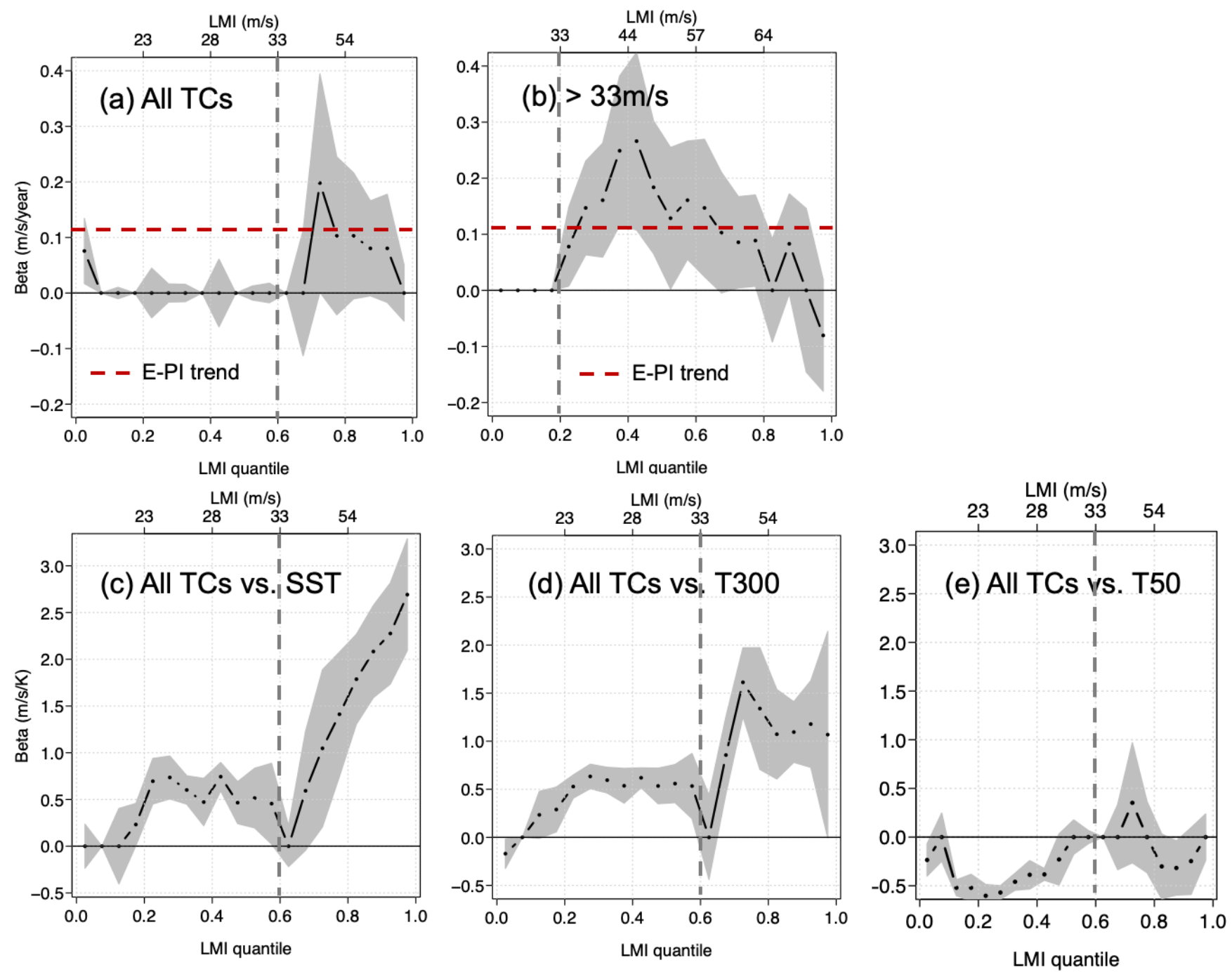

Figure 4: Trends in global LMI quantiles using ADT-HURSAT over the period 1981 to 2017. a) temporal trends for all TCs, b) temporal trends for hurricane strength $\left(>33 \mathrm{~ms}^{-1}\right)$ TCs only, c) trends with SST for all TCs, d) trends with temperature at the 300 hPa level (T300) for all TCs, and e) trends with temperature at $50 \mathrm{hPa}$ (T50) for all TCs. Quantiles vary between 0.025 and 0.0975 with interval 0.05 . The $95 \%$ confidence interval (grey shading) is calculated from bootstrapping with 200 replications. The grey vertical dashed lines are reference lines indicating hurricane category 1 intensity. The slope of the E-PI trend line is shown in horizontal red dashed lines in a) and b). E-PI is calculated using LMI-proximal data. The second x-axis along the top of each panel shows the LMI values corresponding to the LMI quantiles. In b) the second $x$-axis starts at $33 \mathrm{~ms}^{-1}$ (by definition) and remains at $33 \mathrm{~ms}^{-1}$ until the 0.2 quantile. $R$ code is adapted from Elsner and Jagger (2013) available at https://rpubs.com/jelsner/5342.

Figures 4c,d,e show relationships between LMI quantiles over all TCs and SST, temperature at the $300 \mathrm{hPa}$ level (T300) and temperature at the $50 \mathrm{hPa}$ level (T50). As before for the calculation of E-PI, representative environmental temperatures are 
obtained using LMI proximal values. In general, we find large and statistically significant relationships. Intensity has increased significantly with warming SSTs almost universally across LMI quantiles, but with a markedly different response between hurricane strength storms and weaker storms. Tropical storm strength quantiles have increased by approximately $0.6 \mathrm{~ms}^{-1}$ per $\mathrm{K}$, whereas the rate rises rapidly with LMI quantiles above hurricane category 1 strength, reaching a maximum of $2.6 \mathrm{~ms}^{-1}$ per $\mathrm{K}$ at the highest quantiles. This is markedly different behaviour from the temporal trends where the higher rates are located at the middle quantiles. We also note the dip in the trend at quantiles close to about $33 \mathrm{~ms}^{-1}$. These may not be reliable because it coincides with the intensity at which the ADT-HURSAT determinations can be influenced by cirrusobscured eyes.

The response of LMI quantiles to T300 is qualitatively similar to the response to SST but trends plateau for the highest quantiles. This similarity may be expected given the strong correlation between proximal SST and proximal T300 $(\mathrm{R}=$ 390 0.78). The reduced rates of change for the highest quantiles may also be expected given the larger change in upper tropospheric temperature per unit change in SST. As before for SST, hurricane strength TCs exhibit markedly different behaviour to weaker storms: They intensify with T300 warming at approximately twice the rate of weaker storms.

The response of LMI quantiles to T50 temperature (Fig. 4c) shows increasing intensity with cooling across most LMI quantiles but is statistically significant for tropical storm strength storms only. We therefore do not find a significant relationship between trends in hurricane intensity and lower stratosphere temperature. This is consistent with the GCM study by Vecchi et al. (2013) but inconsistent with idealized simulations by Ramsay (2013).

In summary, our analysis of historical records finds that hurricane strength storms exhibit markedly different behaviour to weaker storms in environments of changing temperature profile. Hurricane strength storm intensity increases at twice the rate or more compared to weaker storms within environments of sea surface temperature warming. Hurricane strength storm intensity also increases at twice the rate compared to that of weaker storms in environments of upper tropospheric warming. Despite upper warming having a limited correlation with TC intensity, this result is perhaps unsurprising given the strong correlation between SST and T300 (not shown). The response of hurricane strength storms within environments of lower stratospheric cooling was mixed and did not reach statistical significance.

\subsection{Idealized model experiments}

Towards the goal of isolating and quantifying the effects of temperature profile changes on TC intensity, we turn to idealized simulations which are free from other changes. If the results of these simulations agree with expectation, we can be more confident in attributing observed TC intensity trends to temperature profile changes, which are perhaps more reliably projected by GCMs. On the other hand, if the idealized simulations indicate TC intensity trends that differ markedly from 
https://doi.org/10.5194/wcd-2021-83

Preprint. Discussion started: 4 January 2022

(c) Author(s) 2022. CC BY 4.0 License.

Weather and

Climate Dynamics

(c) (1)

observations, then we can be more confident that other environmental changes are dominant in driving the observed changes. As discussed in Sect. 2.2, numerical simulations were conducted with the CM1 model in an axisymmetric TC configuration.

The 21-member control (present climate) ensemble features an initial period of slightly weakening TC intensity, followed by

steady vortex intensification between simulation hours 12 and 90 (Fig. 5). Considerable ensemble spread develops by hour 50 , with central pressure values ranging from less than $900 \mathrm{hPa}$ to nearly $960 \mathrm{hPa}$ at hour 100 . The simulated ensemble mean TC minimum sea level pressure attained a minimum (maximum intensity) around hour 130, followed by slight weakening and quasi-steady ensemble mean intensity until the end of the simulation. Simulations using a simple Newtonian cooling radiation parameterization generally resulted in weaker TCs (blue lines in Fig. 5), motivating use of an ensemble subset consisting of the 13 members using more complex radiation parameterizations. The complex-radiation subset features reduced ensemble spread, and a lower ensemble-mean central pressure (Table 2). The intensification phase of TCs in the complex radiation members consistently begins earlier in the simulation relative to the simple-radiation subset; for instance, the time required for Pmin to reach $960 \mathrm{hPa}$ is nearly 24 hours faster for the complex radiation members (Fig. 5). We evaluate both the maximum "core" ensemble mean intensity and the steady period at the end of the simulations, consistent with "equilibrium intensity" in the nomenclature of Rousseau-Rizzi et al. (2021). The core intensity corresponds to the LMI.

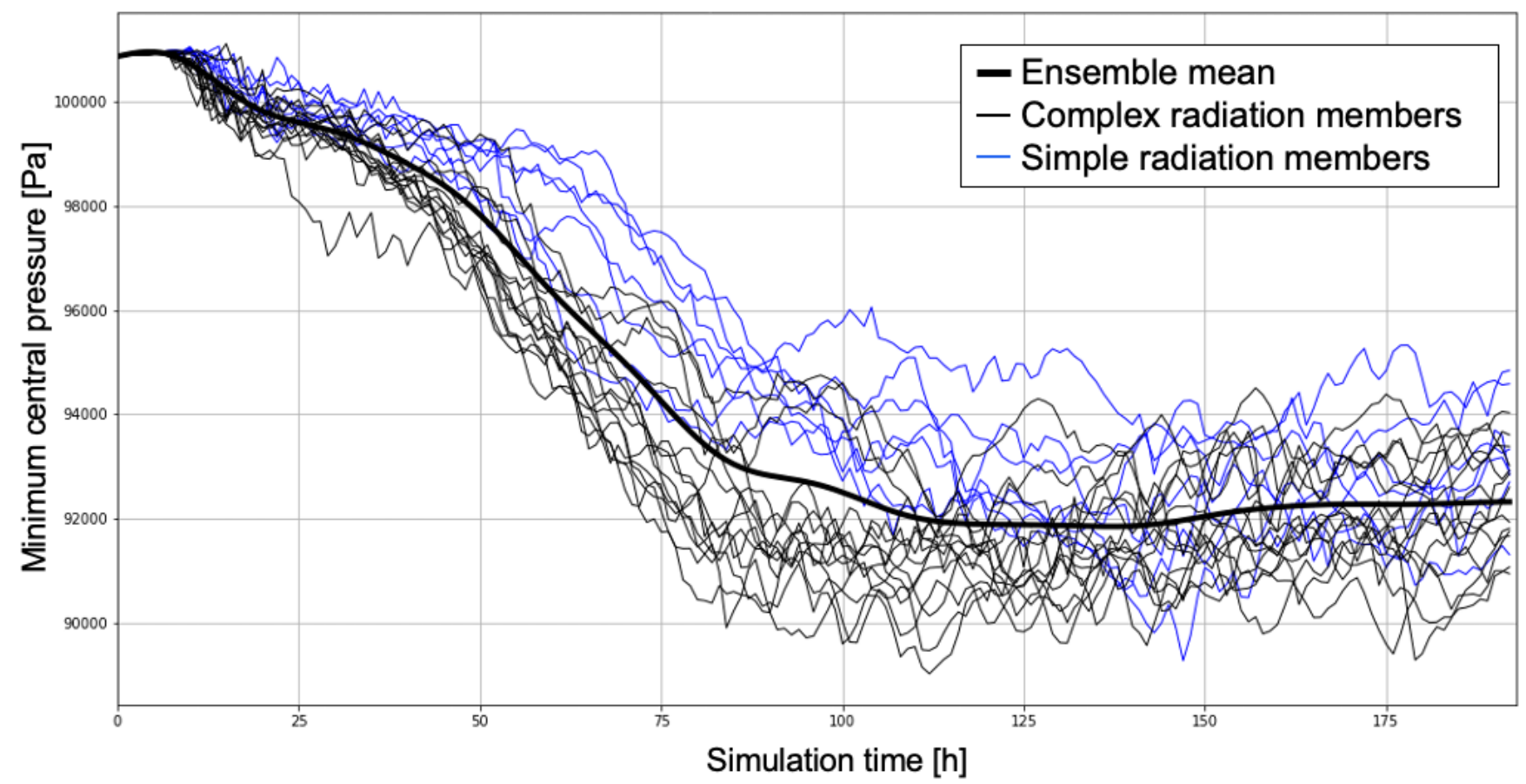

Figure 5: CM1 time series of axisymmetric TC minimum central pressure (Pa) for the default present-day ensemble based on the Dunion moist tropical sounding, split by members with complex- and simple radiation. 
430 For the additional experiments, time series of ensemble-mean maximum near-surface wind speed and minimum central pressure sort out precisely as expected based on theoretical predictions: The present-day simulation features the weakest ensemble-mean TC, while the end-of-century simulations are all stronger, with the mid-century ensemble falling between (Fig. 6, Table 2). This overall trend matches the E-PI calculations in a relative sense (Table 2). One notable difference is the removal of the stratospheric cooling, which had no impact on E-PI but weakened the simulated storm slightly. The GCM435 modified end-of-century environment yields the greatest intensity, with filtered ensemble-mean $P_{\min }$ values approaching 900 $\mathrm{hPa}$ in the complex-radiation ensemble subset (Fig. 6a). This is consistent with the fact that future changes under the CMIP5 RCP8.5 scenario exceed that due to extrapolation of current observed trends (compare purple and red curves in Fig. 6a, and abscissa values in Figs. 1b,c). In all of the simulations, the ensemble mean $P_{\min }$ values were lower than the E-PI calculations, though this difference was reduced for the equilibrium period $P_{\min }$ values. Note that there is uncertainty in the E-PI calculation owing to several choices in parameter settings, as is the case with the CM1 model.

Each ensemble experiment exhibits considerable variability, and the ensemble standard deviations are generally larger than the differences in ensemble mean between the experiments (Fig. 6b, Table 2). That the relative ranking of the experimental ensemble mean intensity matches expectation from theory is notable, but the large ensemble variability provides context regarding statistical robustness, or lack thereof. While we refrain from a dichotomous declaration of "statistically significant" or not (e.g., Amrhein et al., 2019; Wasserstein et al., 2019), we recognize that the differences between the experiments are "small" in this sense. Inspection of the individual ensemble experiments demonstrates that the relative intensity of the different ensemble members exhibits considerable consistency, motivating use of a Wilcoxon signed-rank test (Wilcoxon 1945), appropriate for paired samples (Fig. 6b). Except for the mid-century experiment, small p-values relative to the present-day simulation provide more confidence in the significance of the results relative to what comparison to the overall ensemble mean suggests (top labels in Fig. 6b). Comparison of the end-of-century with the no-upper-warming ensemble yields a signed-rank p-value of 0.13 and compared with the no-stratospheric-cooling ensemble value of 0.29 (not shown). 

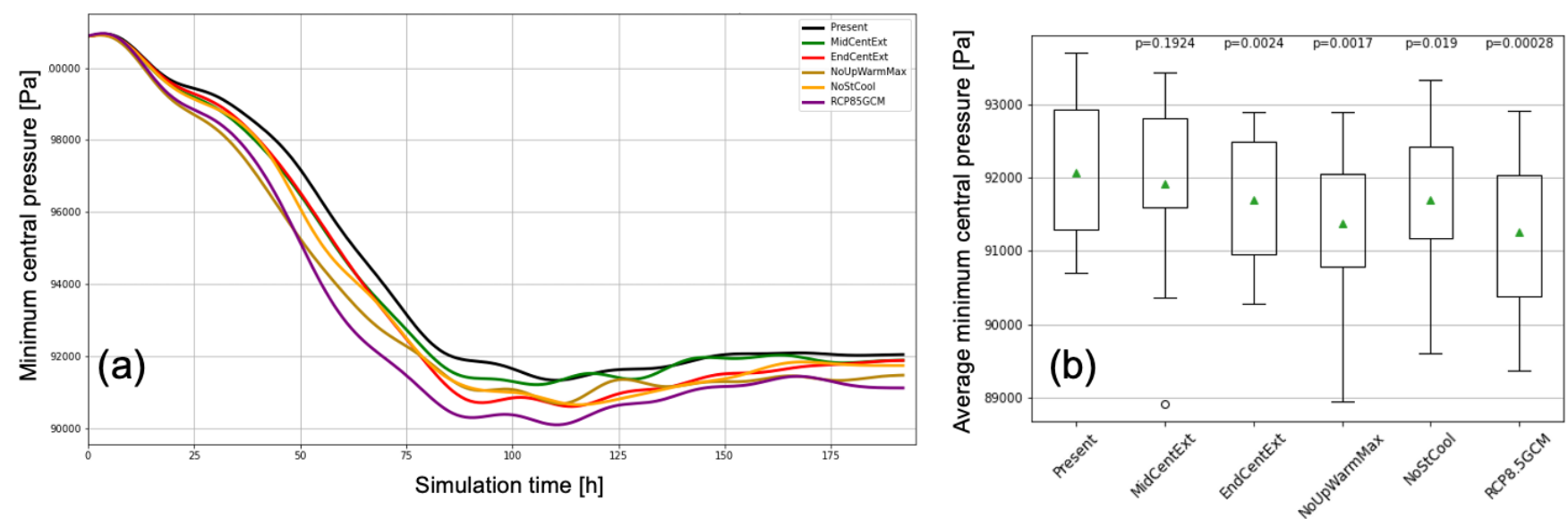

Figure 6: (a) Time series of CM1 ensemble mean minimum sea level pressure (Pa) for present-day simulations with complex radiation parameterization; experiments as indicated in legend at upper right. Ensemble mean time series have been smoothed with a Butterworth filter to remove high-frequency fluctuations. (b) Box plot showing distribution of average equilibrium period minimum central pressure over the 13 complex radiation ensemble members. Mean values are shown as green triangles, p-values from a Wilcoxon paired rank-sum test shown at top for each experiment versus present-climate.

While the smoothed, ensemble mean changes are highly consistent with theoretical expectations, neither the changes predicted by E-PI theory nor those resulting from the numerical simulations are dramatic in terms of $P_{\min }$. For extrapolations of current RAOBCORE trends, the end-of-century ensemble mean is characterized by $P_{\min }$ values that are approximately 10 $\mathrm{hPa}$ lower than for the present-day ensemble. That is not to say that these intensity increases are insignificant, however. Changes in the GCM-modified environment under the RCP8.5 scenario exhibit the strongest changes in ensemble-mean $P_{\min }$, approximately $12 \mathrm{hPa}$ lower. The strengthening seen in the extrapolated RAOBCORE experiments is consistent with that reported for a $2 \mathrm{~K}$ change by Knutson et al. (2020), while the GCM experiment change, accompanied by an SST warming in excess of $3 \mathrm{~K}$, is somewhat less than what would be anticipated from the Knutson et al. (2020) review.

The consistency between the CM1 simulation results and the theoretical E-PI intensity calculations suggests that interpretation of the simulated TC responses to environmental change is consistent with the concept of a Carnot heat engine (e.g., Emanuel, 1988; 1991). Because we use $P_{\min }$ to measure storm intensity, we are not concerned with supergradient wind speeds as analysed by Hakim (2011) and Smith et al. (2008). Our hypothesis in this analysis is that in the quiescent (unsheared) axisymmetric CM1 environment, the TC response to changes in the environmental temperature profile will be consistent with PI theory and the concept of thermodynamic engines. These idealized simulations provide an estimate of the expected effect of such changes on TC characteristics, allowing us to relate the simulation responses back to the observational TC statistics presented in Sect. 3.1. 
We compute the temperature of cloudy, outflowing air in the upper troposphere for each ensemble member in each experiment, and use this information in conjunction with SST to compute the thermodynamic efficiency (see Sect. 2.2) according to Eq. (1):

$E f f=\frac{\text { SST }-T_{\text {out }}}{T_{\text {out }}}$.

485 The outflow temperature is remarkably similar between the different experiments (Table 3). While the warmest outflow is in the GCM-modified experiment, as expected, this does not reach statistical significance. The similarity in outflow temperatures is consistent with the Fixed Anvil Temperature (FAT) hypothesis (Hartmann and Larson, 2002). The FAT hypothesis argues that the environmental cooling rate is largely governed by temperature. This follows from the saturation vapor pressure dependence on temperature via the Clausius-Clapeyron relation. The temperature at which cooling rates rapidly decrease with height (and therefore also the temperature of the outflow) should remain approximately constant. Surface warming therefore raises the altitude of the outflow but has less effect on outflow temperature. In agreement, we find the average pressure altitude of the outflow exhibits considerable difference among the experiments, with the present day ensemble showing the lowest outflow altitude, and the GCM experiment the highest ( $190 \mathrm{hPa}$, Table 3). Although the differences are small relative to the ensemble standard deviation, the no stratospheric cooling and no upper warming maximum experiments exhibit the expected changes in outflow pressure. Interestingly, the average outflow pressure generally reflects an altitude above the upper warming maximum, especially for the stronger TCs in the GCM ensemble.

Table 3: Ensemble mean outflow temperature, pressure, and thermodynamic efficiency computations for the 13-member complex-radiation ensemble subset; radial wind threshold of $1.0 \mathrm{~ms}^{-1}$ and cloud ice threshold of $10^{-5} \mathrm{kgkg}^{-1}$. Ensemble standard deviation (SD) is shown for outflow temperature and pressure. Values apply to the "equilibrium" time window of the simulations, hours 150 to 192.

\begin{tabular}{ccccc}
\hline Experiment & Efficiency & SST (K) & T outflow / SD (K) & P outflow / SD (hPa) \\
\hline Present-day & 0.3429 & 301.15 & $224.25 / 2.73$ & $216.88 / 14.89$ \\
Mid-Century & 0.3459 & 301.77 & $224.22 / 3.31$ & $211.92 / 17.42$ \\
End of Century & 0.3486 & 302.39 & $224.22 / 3.45$ & $207.34 / 17.40$ \\
No upper warming max & 0.3495 & 302.39 & $224.08 / 3.11$ & $205.87 / 15.70$ \\
No stratos. cooling & 0.3465 & 302.39 & $224.57 / 3.20$ & $208.05 / 17.03$ \\
GCM RCP 8.5 & 0.3535 & 304.46 & $224.95 / 3.02$ & $190.59 / 15.11$ \\
\hline
\end{tabular}


For the GCM experiment, the slightly warmer outflow temperature is more than compensated by the increased SST, resulting in the greatest thermodynamic efficiency among the experiments. The GCM experiment also produces the lowest $P_{\min }$ (Table 2). In fact, the numerical simulation experiments ranked by intensity match exactly the ranking in thermodynamic efficiency (Tables 2 and 3). The differences in thermodynamic efficiency between the ensemble members are small in magnitude, but the consistency between these changes and the relative $P_{\min }$ are consistent with expectation, lending confidence to this interpretation.

\section{Concluding Discussion}

510 In a quiescent environment, theory indicates that TC intensities should exhibit considerable sensitivity to changes in the temperature profile, from the sea-surface up into the lower stratosphere (Emanuel, 1991; Kieu and Zhang, 2018; Tao et al., 2020). In this paper, we explored whether observed temperature profile changes are sufficient to explain observed trends in the TC intensity distribution. To do so we worked to isolate and quantify the response of TC intensity to observed trends in environmental temperature using a combination of historical data analysis and idealized numerical modelling. By 515 establishing the linkage between temperature profile changes and TC intensity, we aimed to strengthen understanding and improve interpretation of observed and emerging trends in the TC intensity distribution.

Our historical data analysis focused on global scales spanning four decades to emphasise the scales where thermodynamic change is large and circulation change is minimized. Tropical storm strength intensities show no temporal trend and have therefore not kept pace with rising PI. Hurricane strength storms, however, exhibit significant temporal trends that reach super-PI rates for some intensity quantiles. Storms at these quantiles have therefore closed the gap between realized and maximum potential intensity. This is consistent with our finding that hurricane environments have warmed faster at lower and upper levels than the tropical mean environment.

525 In changing our frame of reference from time to temperature, we again found markedly different sensitivities between tropical storms and hurricane strength storms. Hurricane strength storms intensified at up to four times the rate of tropical storms per unit increase in surface and upper tropospheric temperature. The response of storms within environments of lower stratospheric cooling was mixed and did not reach statistical significance. The differing trend magnitudes among commonly used historical temperature and TC intensity datasets challenges our ability to understand relationships using historical data alone.

We then turned to idealized modelling to further isolate, quantify, and understand the effects of temperature profile changes on TC intensity, and to interpret the empirical statistics. Idealised TC simulations responded in the expected sense to various imposed changes in the temperature profile and agree with TCs operating as heat engines. The imposed historic warming 
trend has faster warming aloft than at the surface, thereby reducing the temperature difference. TC efficiency would therefore be expected to decline, yet our simulations show the opposite: increased TC efficiency. Analysis of TC outflow found little change in the outflow temperature but a rising mean pressure outflow altitude that is located above the altitude of peak upper tropospheric warming. The near constancy of outflow temperatures suggests the increase in thermodynamic efficiency is being driven largely by surface warming. While the FAT hypothesis appears to explain our findings well,

540 further work is needed to understand, at a process level, the extent of applicability of the FAT hypothesis for TCs. The FAT hypothesis for tropical convection has support from observational analysis (Xu et al., 2007) and convection-resolving idealized numerical simulations (Kuang and Hartmann, 2007). Some additional supporting evidence for a FAT for TCs is provided by idealized cloud resolving modelling (Khairoutdinov and Emanuel, 2013) and by analysis of TC cloud top temperatures in ADT-HURSAT data (Kossin, 2015). However, detecting trends in TC cloud top temperatures is complicated

545 by a poleward trend in the latitude of LMI (Kossin, 2015).

Increasing TC efficiency with warming may also explain the fastest temporal trends in intensity for the middle LMI quantiles. With warming, increasing efficiency closes the gap with E-PI. The strongest storms, however, were already close to their E-PI, and weaker storms are more strongly limited by other environmental factors such as shear or dry air.

550 Techniques to simulate weaker storms within the idealized modelling framework are needed to test this hypothesis.

The magnitude of the simulated changes, even for extrapolated trends, is relatively small compared to observed trends in TC characteristics. This suggests that temperature profile changes contributed to some of the observed TC intensity change, but that other environmental factors dominated as the root causes, including, for example, changes in vertical wind shear, humidity, incipient disturbances, or in the large-scale circulation. Removal of the tropical upper-tropospheric warming maximum resulted in modest changes in core or equilibrium TC intensity in the idealized simulations. The consistency between the sense of the idealized simulation changes with theory and observation is consistent with the concept of a TC as a heat engine. Computations of thermodynamic efficiency in the idealized experiments were also consistent with initial hypotheses, and with the sense of changes in TC strength and intensification rate.

Omission of the observed lower stratospheric cooling exerted relatively little influence on TC intensity in our simulations, consistent with our observational analysis. This is consistent with the GCM study by Vecchi et al. (2013). However, the simulated equilibrium TC intensity with omission of stratospheric cooling did weaken, as expected, albeit slightly (Table 2). Axisymmetric simulations out to radiative convective equilibrium by Ramsay (2013) showed stronger vortex intensity with 565 stronger imposed lower stratospheric cooling rates. This was despite much of the outflow confined to the upper troposphere. We agree with Ramsay (2013) and Ferrara et al. (2017) that it is challenging to reconcile contrasting results across different models with different parameter settings and analysis procedures, and across studies using limited historical datasets. 
We hypothesized that observed tropical temperature profile changes also exert predictable influences on trends in the intensification rate of TCs. A preliminary analysis of observations finds historical trends in intensification characteristics (not shown). Specifically, the average onset time of rapid intensification now occurs significantly sooner (by $16 \mathrm{~h}$ ) after the first reported track point than in the first half of our period of record (not shown). Emanuel (2017) notes that sooner rapid intensification has important implications for watches, warnings, and predictability. Our idealized modelling setup did not allow us to pursue intensification due to possible contamination from model initialization and potentially important missing processes in the $2 \mathrm{~d}$ dynamics. Suitable modelling frameworks need to be developed to test this hypothesis.

The differing trends in TC environments compared to the tropical mean environment has implications for climate change studies that use the Pseudo Global Warming (PGW) method. PGW typically applies a long time-average change from GCMs to reanalysis conditions and uses those high-resolution conditions to drive regional model simulations of historical and future weather events (e.g., Lackmann, 2015; Gutmann et al., 2018). TCs may respond differently to environmental change more representative of that taking place locally within TC environments.

Extrapolated observational temperature trends resulted in weaker TC intensity trends relative to change profiles based on an ensemble of CMIP5 GCMs under the RCP 8.5 emission scenario. Future extensions of this work could omit the GCM-based tropical upper warming maximum or stratospheric cooling to determine whether a more substantial change results relative to these exercises with the extrapolated observations. Use of CMIP6 trends would also be useful. Future work could also start from a different base sounding, other than the Dunion (2011) moist tropical sounding. It's possible that different magnitude sensitivities between the historical data analysis and the idealized simulations could be due, in part, to our use of this single profile that allows all simulated storms to reach the highest observed intensities. Base soundings representative of the observed tropical storm and hurricane strength storm environments may yield more nuanced sensitivity to temperature profile change, given permitted variations in outflow altitude. Future work should also include tests with fully 3-D TC simulations; such simulations would allow examination of changes in intensification rate and timing. Finally, more comprehensive physical process studies are needed to interpret the empirical and idealized modelling findings reported here and work towards untangling the factors driving observed intensity changes.

\section{Appendix A}

Table A1: Description of namelist settings for axisymmetric CM1 ensemble simulations.

\begin{tabular}{ccccccc}
\hline member & sfcmodel & oceanmodel & isftcflx & radopt & rterm & ptype \\
\hline 1 & 1 & 1 & 1 & 0 & 1 & 5 \\
2 & 2 & 2 & 2 & 0 & 1 & 5 \\
\hline
\end{tabular}


https://doi.org/10.5194/wcd-2021-83

Preprint. Discussion started: 4 January 2022

(c) Author(s) 2022. CC BY 4.0 License.

\begin{tabular}{|c|c|c|c|c|c|c|}
\hline 3 & 2 & 1 & 1 & 0 & 1 & 5 \\
\hline 4 & 2 & 1 & 2 & 0 & 1 & 5 \\
\hline 5 & 3 & 2 & 2 & 0 & 1 & 5 \\
\hline 6 & 3 & 1 & 1 & 0 & 1 & 5 \\
\hline 7 & 3 & 1 & 2 & 0 & 1 & 5 \\
\hline 8 & 3 & 2 & 2 & 2 & 0 & 3 \\
\hline 9 & 4 & 1 & 1 & 0 & 1 & 5 \\
\hline 10 & 1 & 1 & 1 & 1 & 0 & 5 \\
\hline 11 & 2 & 2 & 2 & 1 & 0 & 5 \\
\hline 12 & 2 & 1 & 1 & 1 & 0 & 5 \\
\hline 13 & 2 & 1 & 2 & 1 & 0 & 5 \\
\hline 14 & 6 & 1 & 1 & 1 & 0 & 5 \\
\hline 15 & 3 & 1 & 1 & 1 & 0 & 5 \\
\hline 16 & 6 & 1 & 2 & 1 & 0 & 3 \\
\hline 17 & 4 & 1 & 1 & 1 & 0 & 3 \\
\hline 18 & 2 & 2 & 2 & 2 & 0 & 3 \\
\hline 19 & 6 & 1 & 1 & 2 & 0 & 3 \\
\hline 20 & 4 & 1 & 1 & 2 & 0 & 3 \\
\hline 21 & 1 & 1 & 1 & 1 & 0 & 5 \\
\hline
\end{tabular}

\section{Code Availability}

600 The pyPI Python software package, developed by Daniel Gilford, is available from https://zenodo.org/badge/latestdoi/247725622 


\section{Code and Data Availability}

The ECMWF reanalysis datasets are available at (https://apps.ecmwf.int/datasets/). The results contain modified Copernicus Climate Change Service information 2020. Neither the European Commission nor ECMWF is responsible for any use that may be made of the Copernicus information or data it contains. IBTrACS data are available from NOAA (https://www.ncdc.noaa.gov/ibtracs/). ADT-HURSAT data are available in the supporting information of Kossin et al. (2020). RAOBCORE data are available at https://www.univie.ac.at/theoret-met/research/raobcore/. CMIP5 model output was obtained from the Program for Climate Model Diagnosis and Intercomparison (PCMDI). The pyPI software used for the E-PI calculations are available from Gilford (2021). R code for the quantile regression modelling presented in Fig. 4 is 610 available at from Elsner and Jagger (2013). The CM1 axisymmetric TC model is available from https://www2.mmm.ucar.edu/people/bryan/cm1/

\section{Author Contribution}

JMD, GML, and AFP designed the analysis and experiments, and carried them out. JMD and GML prepared the manuscript 615 with contributions from AFP.

\section{Competing interests}

The authors declare that they have no conflict of interest.

\section{Acknowledgements}

620 JMD was supported by the Willis Research Network. GML was supported by National Science Foundation (NSF) grant AGS-1546743, awarded to North Carolina State University, and by the NCAR/MMM Visitor Program. We would like to acknowledge data support and high-performance computing support from Cheyenne (doi:10.5065/D6RX99HX) provided by NCAR's Computational and Information Systems Laboratory, sponsored by the National Science Foundation. This material is based upon work supported by the National Center for Atmospheric Research (NCAR); NCAR is a major facility sponsored by the National Science Foundation (NSF) under Cooperative Agreement 1852977. We are grateful to NCAR's George Bryan for developing and maintaining the CM1 model, and Daniel Gilford for the pyPI software used for the E-PI calculations presented in Table 2. We thank NCAR's Chris Davis for suggestions that improved the manuscript.

\section{References}

Amrhein, V., Greenland, S., and McShane, B.: Scientists rise up against statistical significance, Nature, 567, 305-307, https://doi.org/10.1038/d41586-019-00857-9, 2019. 
https://doi.org/10.5194/wcd-2021-83

Preprint. Discussion started: 4 January 2022

(C) Author(s) 2022. CC BY 4.0 License.

(c) (i)
Weather and

Climate Dynamics

Discussions

Bister, M. and Emanuel, K. A.: Dissipative heating and hurricane intensity, Meteor. Atmos. Physics, 65, 233-240, https://doi.org/10.1007/BF01030791, 1998.

Bryan, G. H. and Fritsch, J. M.: A benchmark simulation for moist nonhydrostatic numerical models, Mon. Wea. Rev., 130, 2917-2928, https://doi.org/10.1175/1520-0493(2002)130<2917:ABSFMN>2.0.CO;2, 2002.

Bryan, G. H. and Rotunno, R.: The maximum intensity of tropical cyclones in axisymmetric numerical model simulations, Mon. Wea. Rev., 137, 1770-1789, https://doi.org/10.1175/2008MWR2709.1, 2009a.

640

Bryan, G. H. and Rotunno, R.: Evaluation of an analytical model for the maximum intensity of tropical cyclones, J. Atmos. Sci., 66, 3042-3060, https://doi.org/10.1175/2009JAS3038.1, 2009 b.

Bryan, G. H.: Effects of surface exchange coefficients and turbulence length scales on the intensity and structure of numerically simulated hurricanes, Mon. Wea. Rev., 140, 1125-1143, https://doi.org/10.1175/MWR-D-11-00231.1, 2012.

Butchart, N.: The Brewer-Dobson circulation, Rev. Geophys., 52, 157-184, https://doi.org/10.1002/2013RG000448, 2014.

Cione, J. J., Black, P. G., and Houston, S. H.: Surface observations in the hurricane environment, Mon. Wea. Rev., 128,

1550-1561, https://doi.org/10.1175/1520-0493(2000)128<1550:SOITHE >2.0.CO;2, 2000.

Cordero, E. C. and Forster, P. M.: Stratospheric variability and trends in models used for the IPCC AR4, Atmos. Chem. Phys., 6, 5369-5380, https://doi.org/10.5194/acp-6-5369-2006, 2006.

655 Dee, D. P., Uppala, S. M., Simmons, A. J., Berrisford, P., Poli, P., Kobayashi, S., Andrae, U., Balmaseda, M.A., Balsamo, G., Bauer, D. P., and Bechtold, P.: The ERA-Interim reanalysis: Configuration and performance of the data assimilation system, Quart. J. Roy. Meteor. Soc., 137, 553-597, https://doi.org/10.1002/qj.828, 2011.

Deser, C., Knutti, R., Solomon, S., and Phillips, A.S.: Communication of the role of natural variability in future North 660 American climate, Nat. Clim. Change, 2, 775-779, https://doi.org/10.1038/nclimate1562, 2012.

Dai, A.: Recent climatology, variability, and trends in global surface humidity, J. Climate, 19, 2589-3606, https://doi.org/10.1175/JCLI3816.1, 2006. 
https://doi.org/10.5194/wcd-2021-83

Preprint. Discussion started: 4 January 2022

(C) Author(s) 2022. CC BY 4.0 License.

(c) (i)
Weather and

Climate Dynamics

Discussions

Dunion, J. P.: Rewriting the climatology of the tropical North Atlantic and Caribbean Sea atmosphere, J. Climate, 24, 893908, https://doi.org/10.1175/2010JCLI3496.1, 2011.

Durre, I., Vose, R. S., and Wuertz, D. B.: Overview of the integrated global radiosonde archive, J. Climate, 19, 53-68, https://doi.org/10.1175/JCLI3594.1, 2006.

670

European Centre for Medium-Range Weather Forecasts, 2009: ERA-Interim Project. Research Data Archive at the National Center for Atmospheric Research, Computational and Information Systems Laboratory, Boulder, CO. [Available online at https://doi.org/10.5065/D6CR5RD9.] Accessed 01072021.

675 European Centre for Medium-Range Weather Forecasts, 2019: ERA5 Reanalysis (0.25 Degree Latitude-Longitude Grid). Research Data Archive at the National Center for Atmospheric Research, Computational and Information Systems Laboratory, Boulder, CO. [Available online at https://doi.org/10.5065/BH6N-5N20.] Accessed 01072021.

European Centre for Medium-Range Weather Forecasts, 2020: ERA5.1: Corrections to ERA5 Stratospheric Temperature 680 2000-2006. Research Data Archive at the National Center for Atmospheric Research, Computational and Information Systems Laboratory, Boulder, CO. [Available online at https://doi.org/10.5065/CBTN-V814.] Accessed 01072021.

Elsner, J. B., Kossin, J. P., and Jagger, T. H.: The increasing intensity of the strongest tropical cyclones, Nature, 455, 92-95, https://doi.org/10.1038/nature07234, 2008.

685

Elsner, J. B. and Jagger, T. H.: Hurricane climatology: a modern statistical guide using R. Oxford University Press, https://doi.org/10.1093/oso/9780199827633.001.0001, 2013.

Emanuel, K. A.: An air-sea interaction theory for tropical cyclones. Part I: Steady-state maintenance, J. Atmos. Sci., 43, 690 585-604, https://doi.org/10.1175/1520-0469(1986)043<0585:AASITF>2.0.CO;2, 1986.

Emanuel, K. A.: The dependence of hurricane intensity on climate, Nature, 326, 483-485, https://doi.org/10.1038/326483a0, 1987.

695 Emanuel, K. A.: The maximum intensity of hurricanes, J. Atmos. Sci., 45, 1143-1155, https://doi.org/10.1175/15200469(1988)045<1143:TMIOH>2.0.CO;2, 1988. 
https://doi.org/10.5194/wcd-2021-83

Preprint. Discussion started: 4 January 2022

(C) Author(s) 2022. CC BY 4.0 License.

(c) (i)
Weather and

Climate Dynamics

Discussions

Emanuel, K. A.: The theory of hurricanes, Annu. Rev. Fluid Mech., 23, 179-196, https://doi.org/10.1146/annurev.fl.23.010191.001143, 1991.

Emanuel, K. A.: Hurricanes: Tempests in a greenhouse, Phys. Today, 59, 74-75, 10.1063/1.2349743, 2006.

Emanuel, K. A.: Will global warming make hurricane forecasting more difficult?, Bull. Amer. Meteor. Soc., 98, 495-501, https://doi.org/10.1175/BAMS-D-16-0134.1, 2017.

Emanuel, K. A.: Atlantic tropical cyclones downscaled from climate reanalyses show increasing activity over past 150 years,

705 Nature Comm., 12, 1-8, https://doi.org/10.1038/s41467-021-27364-8, 2021.

Emanuel, K. A. and Rotunno, R.: Self-stratification of tropical cyclone outflow. Part I: Implications for storm structure, J. Atmos. Sci., 68, 2236-2249, https://doi.org/10.1175/JAS-D-10-05024.1, 2011.

710 Emanuel, K. A., Solomon, S., Folini, D., Davis, S., and Cagnazzo, C.: Influence of tropical tropopause layer cooling on Atlantic hurricane activity, J. Climate, 26, 2288-2301, https://doi.org/10.1175/JCLI-D-12-00242.1, 2013.

Ferrara, M., Groff, F., Moon, Z., Keshavamurthy, K., Robeson, S.M. and Kieu, C.: Large-scale control of the lower stratosphere on variability of tropical cyclone intensity, Geophys. Res. Lett., 44, 4313-4323, https://doi.org/10.1002/2017GL073327, 2017.

Fujiwara, M., Hibino, T., Mehta, S. K., Gray, L., Mitchell, D., and Anstey, J.: Global temperature response to the major volcanic eruptions in multiple reanalysis data sets, Atmos. Chem. Phys., 15, 13507-13518, https://doi.org/10.5194/acp-15$13507-2015,2015$.

720

Gentry, M. S. and Lackmann, G. M.: Sensitivity of simulated tropical cyclone structure and intensity to horizontal resolution, Mon. Wea. Rev., 138, 688-704, https://doi.org/10.1175/2009MWR2976.1, 2010.

Gettelman, A., and Coauthors: Multimodel assessment of the upper troposphere and lower stratosphere: Tropics and global trends, J. Geophys. Res., 115, D00M08, https://doi.org/10.1029/2009JD013638, 2010.

Gilford, D. M.: Tropical cyclone potential intensity calculations in Python, Geosci. Model Dev., 14, 2351-2369, https://doi.org/10.5194/gmd-14-2351-2021, 2021. 
https://doi.org/10.5194/wcd-2021-83

Preprint. Discussion started: 4 January 2022

(C) Author(s) 2022. CC BY 4.0 License.

(c) (i)
Weather and

Climate Dynamics

Discussions

730 Gutmann, E. D., Rasmussen, R. M., Liu, C., Ikeda, K., Bruyere, C. L., Done, J. M., Garrè, L., Friis-Hansen, P. and Veldore, V.: Changes in hurricanes from a 13-yr convection-permitting pseudo-global warming simulation, J. Climate, 31, 36433657, https://doi.org/10.1175/JCLI-D-17-0391.1, 2018.

Haimberger, L.: Homogenization of radiosonde temperature time series using innovation statistics, J. Climate, 20, 1377735 1403, https://doi.org/10.1175/JCLI4050.1, 2007.

Haimberger, L., Tavolato, C., and Sperka, S.: Toward elimination of the warm bias in historic radiosonde temperature records-Some new results from a comprehensive intercomparison of upper-air data, J. Climate, 21, 4587-4606, https://doi.org/10.1175/2008JCLI1929.1, 2008.

Haimberger, L., Tavolato, C., and Sperka, S.: Homogenization of the global radiosonde temperature dataset through combined comparison with reanalysis background series and neighboring stations, J. Climate, 25, 8108-8131, https://doi.org/10.1175/JCLI-D-11-00668.1, 2012.

745 Hakim, G.J.: The mean state of axisymmetric hurricanes in statistical equilibrium, J. Atmos. Sci., 68, 1364-1376, https://doi.org/10.1175/2010JAS3644.1, 2011.

Hardiman, S. C., Butchart, N. and Calvo, N.: The morphology of the Brewer-Dobson circulation and its response to climate change in CMIP5 simulations, Quart. J. Roy. Meteor. Soc., 140, 1958-1965, https://doi.org/10.1002/qj.2258, 2014.

Hartmann, D. L. and Larson, K.: An important constraint on tropical cloud-climate feedback, Geophys. Res. Lett., 29(20), 12-1, https://doi.org/10.1029/2002GL015835, 2002.

Hersbach, H., Bell, B., Berrisford, P., Hirahara, S., Horányi, A., Muñoz-Sabater, J., Nicolas, J., Peubey, C., Radu, R.,

755 Schepers, D. and Simmons, A.: The ERA5 global reanalysis, Quart. J. Roy. Meteor. Soc., 146, 1999-2049, https://doi.org/10.1002/qj.3803, 2020.

Hill, K. A. and Lackmann, G. M.: The impact of future climate change on TC intensity and structure: A downscaling approach, J. Climate, 24, 4644-4661, https://doi.org/10.1175/2011JCLI3761.1, 2011.

Holland, G. J.: The maximum potential intensity of tropical cyclones, J. Atmos. Sci., 54, 2519-2541, https://doi.org/10.1175/1520-0469(1997)054<2519:TMPIOT>2.0.CO;2, 1997. 
https://doi.org/10.5194/wcd-2021-83

Preprint. Discussion started: 4 January 2022

(C) Author(s) 2022. CC BY 4.0 License.

(c) (i)
Weather and

Climate Dynamics

Discussions

Holland, G. and Bruyère, C. L.: Recent intense hurricane response to global climate change, Clim. Dyn., 42, 617-627, https://doi.org/10.1007/s00382-013-1713-0, 2014.

Jewson, S. and Lewis, N.: Statistical decomposition of the recent increase in the intensity of tropical storms, Oceans, 1, 311-325, https://doi.org/10.3390/oceans1040021, 2020.

770 Jung, C. and Lackmann, G. M.: Extratropical transition of Hurricane Irene (2011) in a changing climate, J. Climate, 32, 4847-4871, https://doi.org/10.1175/JCLI-D-18-0558.1, 2019.

Khairoutdinov, M. and Emanuel, K.: Rotating radiative-convective equilibrium simulated by a cloud-resolving model, J. Adv. Model. Earth Syst., 5, 816-825, https://doi.org/10.1002/2013MS000253, 2013.

Kieu, C. and Zhang, D. L.: The control of environmental stratification on the hurricane maximum potential intensity, Geophys. Res. Lett., 45, 6272-6280, https://doi.org/10.1029/2018GL078070, 2018.

Klotzbach, P. and Landsea, C.: Extremely intense hurricanes: Revisiting Webster et al. (2005) after 10 years, J. Climate, 28, 780 7621-7629, https://doi.org/10.1175/JCLI-D-15-0188.1, 2015.

Klotzbach, P. J., Bell, M. M., Bowen, S. G., Gibney, E. J., Knapp, K. R., and Schreck III, C. J.: Surface pressure a more skillful predictor of normalized hurricane damage than maximum sustained wind, Bull. Amer. Meteor. Soc., 101, E830 E846, https://doi.org/10.1175/BAMS-D-19-0062.1, 2020.

Knapp, K. R. and Kruk, M. C.: Quantifying interagency differences in tropical cyclone best-track wind speed estimates, Mon. Wea. Rev., 138, 1459-1473, https://doi.org/10.1175/2009MWR3123.1, 2010.

Knapp, K. R., Kruk, M. C., Levinson, D. H., Diamond, H. J. and Neumann, C. J.: The international best track archive for climate stewardship (IBTrACS) unifying tropical cyclone data, Bull. Amer. Meteor. Soc., 91, 363-376, https://doi.org/10.1175/2009BAMS2755.1, 2010.

Knutson, T. R., McBride, J. L., Chan, J., Emanuel, K., Holland, G., Landsea, C., Held, I., Kossin, J. P., Srivastava, A. K., and Sugi, M.: Tropical cyclones and climate change, Nature geoscience, 3, 157-163, https://doi.org/10.1038/ngeo779, 2010. 
https://doi.org/10.5194/wcd-2021-83

Preprint. Discussion started: 4 January 2022

(C) Author(s) 2022. CC BY 4.0 License.

(c) (i)
Weather and

Climate Dynamics

Discussions

Knutson, T., Camargo, S.J., Chan, J.C., Emanuel, K., Ho, C.H., Kossin, J., Mohapatra, M., Satoh, M., Sugi, M., Walsh, K. and Wu, L.: Tropical cyclones and climate change assessment: Part I: Detection and attribution, Bull. Amer. Meteor. Soc., 100, 1987-2007, https://doi.org/10.1175/BAMS-D-18-0189.1, 2019.

800 Knutson, T., Camargo, S.J., Chan, J.C., Emanuel, K., Ho, C.H., Kossin, J., Mohapatra, M., Satoh, M., Sugi, M., Walsh, K. and $\mathrm{Wu}, \mathrm{L} .:$ Tropical cyclones and climate change assessment: Part II: Projected response to anthropogenic warming, Bull. Amer. Meteor. Soc., 101, E303-E322, https://doi.org/10.1175/BAMS-D-18-0194.1, 2020.

Kossin, J. P.: Validating atmospheric reanalysis data using tropical cyclones as thermometers, Bull. Amer. Meteor. Soc, 96, 1089-1096, https://doi.org/10.1175/BAMS-D-14-00180.1, 2015.

Kossin, J. P., Olander, T. L. and Knapp, K. R.: Trend analysis with a new global record of tropical cyclone intensity, J. Climate, 26, 9960-9976, https://doi.org/10.1175/JCLI-D-13-00262.1, 2013.

810 Kossin, J. P., Knapp, K. R., Olander, T. L. and Velden, C. S.: Global increase in major tropical cyclone exceedance probability over the past four decades, Proc. Nat. Acad. Sci., 117, 11975-11980, https://doi.org/10.1073/pnas.1920849117, 2020.

Kuang, Z. and Hartmann, D. L.: Testing the fixed anvil temperature hypothesis in a cloud-resolving model, J. Climate, 20, 815 2051-2057, https://doi.org/10.1175/JCLI4124.1, 2007.

Lackmann, G.M.: Hurricane Sandy before 1900 and after 2100, Bull. Amer. Meteor. Soc., 96, 547-560, https://doi.org/10.1175/BAMS-D-14-00123.1, 2015.

820 Landsea, C. W., Harper, B. A., Hoarau, K., and Knaff, J. A.: Can we detect trends in extreme tropical cyclones? , Science, 313, 452-454, https://doi.org/10.1126/science.1128448, 2006.

Meehl, G. A., Washington, W. M., Ammann, C. M., Arblaster, J. M., Wigley, T. M. L. and Tebaldi, C.: Combinations of natural and anthropogenic forcings in twentieth-century climate, J. Climate, 17, 3721-3727, https://doi.org/10.1175/15200442(2004)017<3721:CONAAF>2.0.CO;2, 2004.

Meehl G. A., Washington W. M., Arblaster J. M., Hu A., Teng H., Tebaldi C., Sanderson B., Lamarque J. F., Conley A., Strand W. G., and White J. B. III: Climate system response to external forcings and climate change projections in CCSM4, J. Climate, 25, 3661-3683. https://doi.org/10.1175/JCLI-D-11-00240.1, 2012. 
https://doi.org/10.5194/wcd-2021-83

Preprint. Discussion started: 4 January 2022

(C) Author(s) 2022. CC BY 4.0 License.

(c) (i)
Weather and

Climate Dynamics

Discussions

830

Mitchell, D. M., Thorne, P. W., Stott, P. A. and Gray, L. J.: Revisiting the controversial issue of tropical tropospheric temperature trends, Geophys. Res. Lett., 40, 2801-2806, https://doi.org/10.1002/grl.50465, 2013.

O'Gorman, P. A. and Singh, M. S.: Vertical structure of warming consistent with an upward shift in the middle and upper troposphere, Geophys. Res. Lett., 40, 1838-1842, https://doi.org/10.1002/grl.50328, 2013.

Pauluis, O. M. and Zhang, F.: Reconstruction of thermodynamic cycles in a high-resolution simulation of a hurricane, J. Atmos. Sci., 74, 3367-3381, https://doi.org/10.1175/JAS-D-16-0353.1, 2017.

Persing, J., Montgomery, M. T., McWilliams, J. C., and Smith, R. K.: Asymmetric and axisymmetric dynamics of tropical cyclones, Atmos. Chem. Phys., 13, 12299-12341, https://doi.org/10.5194/acp-13-12299-2013, 2013.

Philipona, R., Mears, C., Fujiwara, M., Jeannet, P., Thorne, P., Bodeker, G., Haimberger, L., Hervo, M., Popp, C., Romanens, G. and Steinbrecht, W.: Radiosondes show that after decades of cooling, the lower stratosphere is now warming, J. Geophys. Res.: Atmospheres, 123, 12-509, https://doi.org/10.1029/2018JD028901, 2018.

Po-Chedley, S. and Fu, Q.: Discrepancies in tropical upper tropospheric warming between atmospheric circulation models and satellites, Env. Res. Lett., 7, 044018, https://doi.org/10.1088/1748-9326/7/4/044018, 2012.

850 Prein, A. F., Liu, C., Ikeda, K., Trier, S. B., Rasmussen, R. M., Holland, G. J. and Clark, M. P.: Increased rainfall volume from future convective storms in the US, Nat. Clim. Change, 7, 880-884, https://doi.org/10.1038/s41558-017-0007-7, 2017.

Prein, A. F. and Heymsfield, A. J.: Increased melting level height impacts surface precipitation phase and intensity, Nat. Clim. Change, 10, 771-776, https://doi.org/10.1038/s41558-020-0825-x, 2020.

Rahmstorf, S., Foster, G., and Cahill, N.: Global temperature analysis: Recent trends and some pitfalls, Env. Res. Lett., 12, 054001, https://doi.org/10.1088/1748-9326/aa6825, 2017.

Ramaswamy, V., Schwarzkopf, M. D., Randel, W. J., Santer, B. D., Soden, B. J. and Stenchikov, G. L.: Anthropogenic and natural influences in the evolution of lower stratospheric cooling, Science, 311, 1138-1141, https://doi.org/10.1126/science.1122587, 2006. 
https://doi.org/10.5194/wcd-2021-83

Preprint. Discussion started: 4 January 2022

(C) Author(s) 2022. CC BY 4.0 License.

(c) (i)
Weather and

Climate Dynamics

Discussions

Ramsay, H. A.: The effects of imposed stratospheric cooling on the maximum intensity of tropical cyclones in axisymmetric radiative-convective equilibrium, J. Climate, 26, 9977-9985, https://doi.org/10.1175/JCLI-D-13-00195.1, 2013.

865

Rotunno, R. and Emanuel, K. A.: An air-sea interaction theory for tropical cyclones. Part II: Evolutionary study using a nonhydrostatic axisymmetric numerical model, J. Atmos. Sci., 44, 542-561, https://doi.org/10.1175/1520-

0469(1987)044<0542:AAITFT>2.0.CO;2, 1987.

870 Rousseau-Rizzi, R. and Emanuel, K.: An evaluation of hurricane superintensity in axisymmetric numerical models, J. Atmos. Sci., 76, 1697-1708, https://doi.org/10.1175/JAS-D-18-0238.1, 2019.

Rousseau-Rizzi, R., Rotunno, R., and Bryan, G.: A Thermodynamic Perspective on Steady-State Tropical Cyclones, J. Atmos. Sci., 78, 583-593, https://doi.org/10.1175/JAS-D-20-0140.1, 2021.

Santer, B. D., Wigley, T. M., Mears, C., Wentz, F. J., Klein, S. A., Seidel, D. J., Taylor, K. E., Thorne, P. W., Wehner, M. F., Gleckler, P. J. and Boyle, J. S.: Amplification of surface temperature trends and variability in the tropical atmosphere, Science, 309, 1551-1556, DOI: 10.1126/science.1114867, 2005.

880 Santer, B. D. and Co-authors: Consistency of modelled and observed temperature trends in the tropical troposphere, Int. J. Climatol., 28, 1703-1722, https://doi.org/10.1002/joc.1756, 2008.

Shen, W., Tuleya, R. E. and Ginis, I.: A sensitivity study of the thermodynamic environment on GFDL model hurricane intensity: Implications for global warming, J. Climate, 13, 109-121, https://doi.org/10.1175/15200442(2000)013<0109:ASSOTT>2.0.CO;2, 2000.

Sherwood, S. C., Lanzante, J. R. and Meyer, C. L.: Radiosonde daytime biases and late-20th century warming, Science, 309, 1556-1559, https://doi.org/10.1126/science.1115640, 2005.

890 Schreck III, C. J., Knapp, K. R. and Kossin, J. P.: The impact of best track discrepancies on global tropical cyclone climatologies using IBTrACS, Mon. Wea. Rev. 142, 3881-3899, https://doi.org/10.1175/MWR-D-14-00021.1, 2014.

Simmons, A. J., Poli, P., Dee, D. P., Berrisford, P., Hersbach, H., Kobayashi, S. and Peubey, C.: Estimating low-frequency variability and trends in atmospheric temperature using ERA-Interim, Quart. J. Roy. Meteor. Soc., 140, 329-353,

895 https://doi.org/10.1002/qj.2317, 2014. 
https://doi.org/10.5194/wcd-2021-83

Preprint. Discussion started: 4 January 2022

(C) Author(s) 2022. CC BY 4.0 License.

(c) (i)
Weather and

Climate Dynamics

Discussions

Simmons, A. J., Soci, C., Nicolas, J., Bell, B., Berrisford, P., Dragani, R., Flemming, J., Haimberger, L., Healey, S. B., Hersbach, H., Horányi, A., Inness, A., Muñoz-Sabater, J., Radu, R. and Schepers, D.: Global stratospheric temperature bias and other stratospheric aspects of ERA5 and ERA5.1. Technical Memorandum 859, ECMWF, Reading, UK, $10.21957 /$ rcxqfmg0, 2020.

Smith, R. K., Montgomery, M. T., and Nguyen, S. V.: Axisymmetric dynamics of tropical cyclone intensification in a three dimensional model, Quart. J. Roy. Meteor. Soc., 134, 337-351, https://doi.org/10.1175/JAS-D-17-0179.1, 2008.

905 Strazzo, S. E., Elsner, J. B. and LaRow, T. E.: Quantifying the sensitivity of maximum, limiting, and potential tropical cyclone intensity to SST: Observations versus the FSU/COAPS global climate model, J. Adv. Mod. Earth Systems, 7, 586599, https://doi.org/10.1002/2015MS000432, 2015.

Tao, D., Rotunno, R., and Bell, M.: Lilly’s Model for Steady-State Tropical Cyclone Intensity and Structure, J. Atmos. Sci., 77, 3701-3720, https://doi.org/10.1175/JAS-D-20-0057.1, 2020.

Thompson, D. W. J., Seidel, D. J., Randel, W. J., Zou, C. Z., Butler, A. H., Mears, C., Osso, A., Long, C., and Lin, R.: The mystery of recent stratospheric temperature trends, Nature, 491, 692-697, https://doi.org/10.1038/nature11579, 2012.

915 Thorne, P. W., Lanzante, J. R., Peterson, T. C., Seidel, D. J. and Shine, K. P.: Tropospheric temperature trends: History of an ongoing controversy, Wiley Interdisciplinary Reviews: Clim. Change, 2, 66-88, https://doi.org/10.1002/wcc.80, 2011.

Ting, M., Kossin, J. P., Camargo, S. J. and Li, C.: Past and future hurricane intensity change along the US east coast, Scientific reports, 9, 1-8, https://doi.org/10.1038/s41598-019-44252-w, 2019.

Tuleya, R. E., Bender, M. A., Knutson, T. R., Sirutis, J. J., Thomas, B., and Ginis, I.: Impact of upper tropospheric temperature anomalies and vertical wind shear on tropical cyclone evolution using an idealized version of the operational GFDL hurricane model, J. Atmos. Sci., 73, 3803-3820, https://doi.org/10.1175/JAS-D-16-0045.1, 2016.

Uppala, S. M., Kållberg, P. W., Simmons, A. J., Andrae, U., Bechtold, V. D. C., Fiorino, M., Gibson, J. K., Haseler, J., Hernandez, A., Kelly, G. A. and Li, X.: The ERA-40 re-analysis, Quart. J. Roy. Meteor. Soc., 131, 2961-3012, https://doi.org/10.1256/qj.04.176, 2005.

Vecchi, G. A., Fueglistaler, S., Held, I. M., Knutson, T. R., Zhao, M.: Impacts of atmospheric temperature changes on tropical cyclone activity, J. Climate, 26, 3877-3891, https://doi.org/10.1175/JCLI-D-12-00503.1, 2013. 
https://doi.org/10.5194/wcd-2021-83

Preprint. Discussion started: 4 January 2022

(c) Author(s) 2022. CC BY 4.0 License.

(c) (1)

Weather and

Climate Dynamics

Discussions

Wang, Y.: Vortex Rossby waves in a numerically simulated tropical cyclone. Part I: Overall structure, potential vorticity, and kinetic energy budgets, J. Atmos. Sci., 59, 1213-1238, https://doi.org/10.1175/1520-

0469(2002)059<1213:VRWIAN>2.0.CO;2, 2002.

935 Wasserstein, R. L., Schirm, A. L., and Lazar, N. A.: Moving to a world beyond "p < 0.05" , The American Statistician, 73, 1537-2731, https://doi.org/10.1080/00031305.2019.1583913, 2019.

Wilcoxon, F.: Individual comparisons by ranking methods, Biom. Bull., 1, 80-83, https://doi.org/10.2307/3001968, 1945.

Xu, K. M., Wong, T., Wielicki, B. A., Parker, L., Lin, B., Eitzen, Z. A. and Branson, M.: Statistical analyses of satellite

940 cloud object data from CERES. Part II: Tropical convective cloud objects during 1998 El Niño and evidence for supporting the fixed anvil temperature hypothesis, J. Climate, 20, 819-842, https://doi.org/10.1175/JCLI4069.1, 2007. 